\title{
A Role for an Hsp70 Nucleotide Exchange Factor in the Regulation of Synaptic Vesicle Endocytosis
}

\author{
Jennifer R. Morgan, ${ }^{1,2}$ Jianwen Jiang, ${ }^{3}$ Paul A. Oliphint, ${ }^{2}$ Suping Jin, ${ }^{3}$ Luis E. Gimenez, ${ }^{3}$ David J. Busch, ${ }^{2}$ \\ Andrea E. Foldes, ${ }^{2}$ Yue Zhuo, ${ }^{3}$ Rui Sousa, ${ }^{3}$ and Eileen M. Lafer ${ }^{3}$ \\ ${ }^{1}$ Eugene Bell Center for Regenerative Biology and Tissue Engineering, Marine Biological Laboratory, Woods Hole, Massachusetts $02543,{ }^{2}$ Section of \\ Molecular Cell and Developmental Biology, Institute for Cell and Molecular Biology, Institute for Neuroscience, University of Texas at Austin, Austin, Texas \\ 78712, and ${ }^{3}$ Department of Biochemistry and Center for Biomedical Neuroscience, University of Texas Health Science Center at San Antonio, San Antonio, \\ Texas 78212
}

Neurotransmission requires a continuously available pool of synaptic vesicles (SVs) that can fuse with the plasma membrane and release their neurotransmitter contents upon stimulation. After fusion, SV membranes and membrane proteins are retrieved from the presynaptic plasma membrane by clathrin-mediated endocytosis. After the internalization of a clathrin-coated vesicle, the vesicle must uncoat to replenish the pool of SVs. Clathrin-coated vesicle uncoating requires ATP and is mediated by the ubiquitous molecular chaperone Hsc70. In vitro, depolymerized clathrin forms a stable complex with $\mathrm{Hsc} 70^{\star} \mathrm{ADP}$. This complex can be dissociated by nucleotide exchange factors (NEFs) that release ADP from Hsc70, allowing ATP to bind and induce disruption of the clathrin:Hsc70 association. Whether NEFs generally play similar roles in vesicle trafficking in vivo and whether they play such roles in SV endocytosis in particular is unknown. To address this question, we used information from recent structural and mechanistic studies of Hsp70:NEF and Hsp70:co-chaperone interactions to design a NEF inhibitor. Using acute perturbations at giant reticulospinal synapses of the sea lamprey (Petromyzon marinus), we found that this NEF inhibitor inhibited SV endocytosis. When this inhibitor was mutated so that it could no longer bind and inhibit Hsp110 (a NEF that we find to be highly abundant in brain cytosol), its ability to inhibit SV endocytosis was eliminated. These observations indicate that the action of a NEF, most likely Hsp110, is normally required during SV trafficking to release clathrin from Hsc70 and make it available for additional rounds of endocytosis.

\section{Introduction}

During synaptic transmission, synaptic vesicles (SVs) are recycled by clathrin-mediated endocytosis, a process involving multiple proteins (Saheki and De Camilli, 2012). Clathrin assembles into a lattice on the plasma membrane and deforms it into a spherical vesicle (Morgan et al., 2002). Dynamin then severs the clathrin-coated vesicle (CCV) from the membrane (Takei et al., 1995; Mettlen et al., 2009), and the clathrin coat is subsequently removed in an ATP-requiring reaction mediated by the Hsc70 chaperone and the J-protein co-chaperone auxilin (Fig. 1) (Ungewickell et al., 1995; Morgan et al., 2001; Yim et al., 2010). Hsc70 plays a direct role in clathrin disassembly, with its proteinbinding domain engaging the extended tails at the $\mathrm{C}$ termini of clathrin heavy chains to induce coat dissociation (Rapoport et al.,

Received Sept. 21, 2012; revised March 20, 2013; accepted March 29, 2013.

Author contributions: J.R.M., R.S., and E.M.L. designed research;J.R.M., J.J., P.A.O., S.J., L.E.G., D.J.B., A.E.F., Y.Z., R.S., and E.M.L. performed research; J.R.M., J.J., P.A.O., S.J., L.E.G., D.J.B., A.E.F., Y.Z., R.S., and E.M.L. analyzed data; J.R.M., R.S., and E.M.L. wrote the paper.

This work was supported by the National Institutes of Health (Grant \#NS029051 to E.M.L. and Grant \#NS078165 to J.R.M.). We thank Dr. Dwight Romanovicz and the Institute for Cell and Molecular Biology Microscopy Core Facility at University of Texas-Austin for technical assistance with EM and Dr. Naila Alieva for assistance with the pilot EM studies.

The authors declare no competing financial interests.

Correspondence should be addressed to Eileen M. Lafer, Department of Biochemistry, University of Texas Health Science Center at San Antonio, 7703 Floyd Curl Drive, San Antonio, TX 78229. E-mail: Lafer@uthscsa.edu.

DOI:10.1523/JNEUROSCI.4505-12.2013

Copyright $\odot 2013$ the authors $\quad 0270-6474 / 13 / 338009-13 \$ 15.00 / 0$
2008; Xing et al., 2010). The J-protein co-chaperone uses its J and clathrin-binding domains to, respectively, bind Hsc70 and recruit it to the coat (Fig. 1A). After ATP hydrolysis by Hsc70 and uncoating, the vesicle is refilled with neurotransmitters and returned to the SV pool (Saheki and De Camilli, 2012). Acute or genetic perturbation of any of these stages of clathrin-mediated endocytosis impairs synaptic transmission and has been used to identify the functional roles of the actors in this process (Zhang, 2003; Augustine et al., 2006; Jung and Haucke, 2007; Dittman and Ryan, 2009; Saheki and De Camilli, 2012). However, it is still unclear how pools of unpolymerized clathrin are maintained at synapses to sustain multiple rounds of SV endocytosis.

In vitro, clathrin that is dissociated from CCVs or from membrane free clathrin coats (baskets) remains associated with Hsc70*ADP (Jiang et al., 2000). Persistent association of clathrin ${ }^{\star} \mathrm{Hsc} 70^{\star} \mathrm{ADP}$ complexes may also occur in vivo and may not be merely an incidental product of the disassembly reaction, but may also be important in preventing unregulated clathrin polymerization (Newmyer and Schmid, 2001). However, if clathrin normally forms a persistent complex with Hsc70 after uncoating, then this raises the question of how it is released from $\mathrm{Hsc} 70^{*} \mathrm{ADP}$ when needed for SV endocytosis. We showed that, in vitro, Hsp70 nucleotide exchange factors (NEFs) such as Hsp110 or Bagl stimulate Hsc70-mediated disassembly of clathrin baskets when Hsc70 is limiting because they promote the dissociation of clathrin ${ }^{\star} \mathrm{Hsc} 70^{\star} \mathrm{ADP}$ complexes, generating free Hsc70 
A

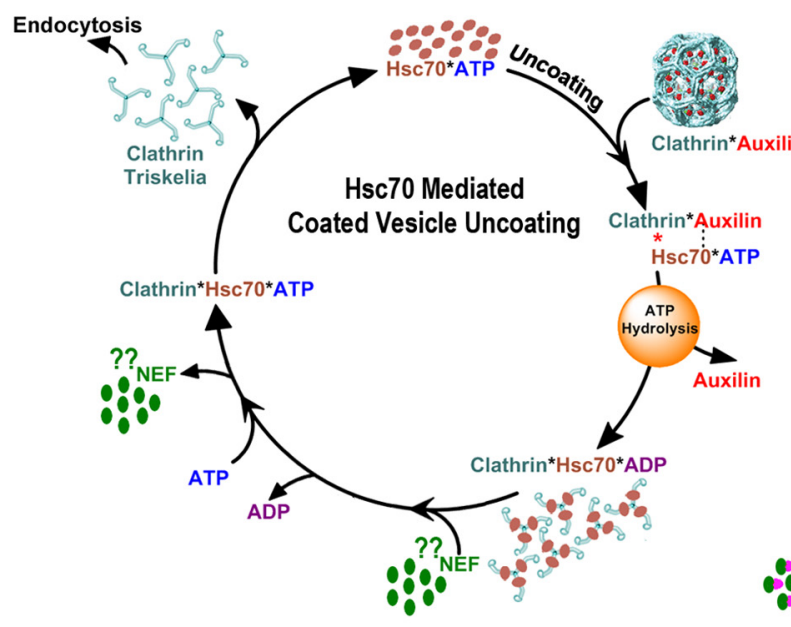

B

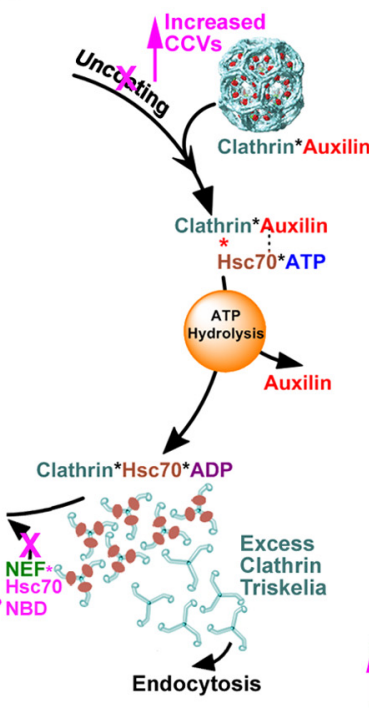

C

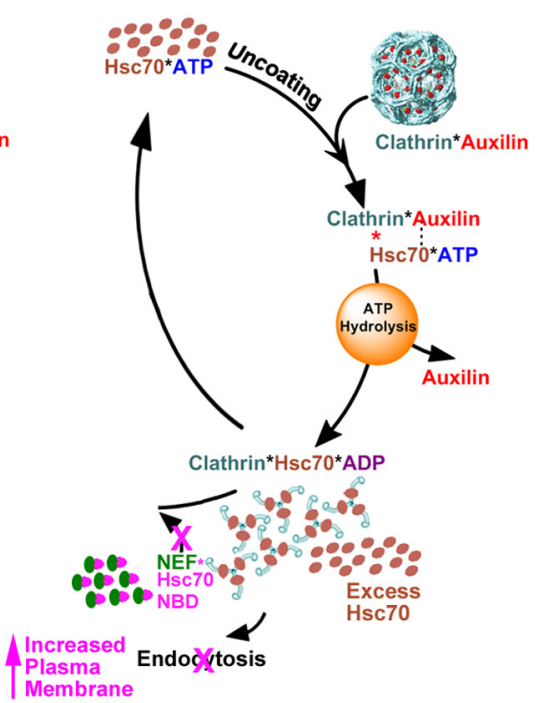

Figure 1. Hsc70-mediated coated vesicle uncoating. $\boldsymbol{A}$, In all panels, the color of the text matches the color of the corresponding molecule. Clathrin coat disassembly begins when auxilin binds clathrin and recruits Hsc70:ATP to the clathrin coat. After ATP hydrolysis, the clathrin coat disassembles, auxilin is released, and clathrin forms a long-lived complex with Hsc70:ADP. Interaction of clathrin:Hsc70:ADP with an NEF results in the release of ADP, and subsequent binding of ATP to Hsc70 results in release of the NEF and clathrin. The role of auxilin and $\mathrm{Hsc70}$ in this process has been demonstrated in vivo, but although NEFs have been shown to stimulate uncoating in vitro (Schuermann et al., 2008), there is as yet no data on the role of Hsp70 NEFs in vesicle trafficking in vivo. B, Expected effects of an NEF inhibitor if the amount of clathrin in neuronal cytosol is greater than the amount of Hsc70. With free clathrin available, plasma membrane endocytosis can occur, but with most Hsc70 sequestered in clathrin*Hsc70*ADP complexes, uncoating would be inhibited and an increased number of CCVs would be observed. C, Expected effects of an NEF inhibitor if the amount of $\mathrm{Hsc} 70$ is greater than the amount of clathrin. With free $\mathrm{Hsc} 70$ available, uncoating can occur, but with most clathrin sequestered in clathrin*Hsc70*ADP complexes, plasma membrane endocytosis would be inhibited and increased plasma membrane area would be observed.

that can participate in further cycles of disassembly (Schuermann et al., 2008). Because the activity of the NEFs results in release of both free Hsc70 and clathrin in vitro, this raises the possibility that, in vivo, NEFs are involved in releasing Hsc70 and clathrin from clathrin ${ }^{\star} \mathrm{Hsc} 70^{\star} \mathrm{ADP}$ complexes when required for endocytosis.

Here, we engineered inhibitors that specifically bind and inhibit Hsp70 NEFs and used them to inhibit NEF activity acutely at synapses. Together with quantitative Western blot analyses of the abundance of clathrin, Hsc70, and several NEFs in brain cytosol, our results indicate that clathrin association with $\mathrm{Hsc70}$ limits the availability of free clathrin for endocytosis, and that a NEF, most likely Hsp110, is responsible for releasing clathrin from Hsc70 to allow endocytosis during SV recycling.

\section{Materials and Methods}

Mutagenesis and protein preparation. DNAs encoding mutant Hsc70 nucleotide-binding domains (NBDs) were constructed using the QuikChange Site-Directed Mutagenesis Kit (Agilent Technologies) and cloned into $\mathrm{pET} 28 \mathrm{a}(+)$ (Novagen). His tagged proteins were purified by Ni-NTA agarose (Qiagen), followed by anion exchange on Q-Sepharose, pH 8.0 (GE Healthcare). Clathrin and AP2 were purified from bovine brain CCVs as described previously (Hao et al., 1999; Jiang et al., 2007). Recombinant bovine Hsc70, human, and yeast his-Hsp110, human GSTBag1, bovine his-auxilin (547-910), bovine his-Hsc70 NBD, and mouse GST-AP180 were prepared as described previously (Hao et al., 1999; Jiang et al., 2007; Schuermann et al., 2008). Yeast Hsp110 (Sse1) was used in the experiments shown in Figure 2; all other experiments were performed with human Hsp110.

Analysis of Hsc70:Hsp 110 complex formation and ATPase assays. Native PAGE of Hsp110:Hsc70 NBD and Bag1:Hsc70 NBD complex formation was as described previously (Shaner et al., 2006; Schuermann et al., 2008). Multiple round ATPase assays were performed at room temperature with $0.1 \mathrm{~mm} \mathrm{ATP}$ and $0.1 \mathrm{mCi} / \mathrm{ml} 3000 \mathrm{mCi} / \mathrm{mm} \alpha^{32} \mathrm{P}$-ATP in $50 \mu \mathrm{l}$ reactions in $10 \mathrm{~mm}$ Tris, $\mathrm{pH}$ 8.0, $50 \mathrm{~mm} \mathrm{KCl,} 5 \mathrm{~mm} \mathrm{MgCl}_{2}$, and $1 \mathrm{~mm}$ DTT with the proteins indicated in Figure 2 at $2 \mu \mathrm{M}$, with the exception of auxilin, which was at $20 \mu \mathrm{m}$. Reactions were initiated by adding $25 \mu \mathrm{l}$ of $2 \times$ ATP mixture to $25 \mu \mathrm{l}$ of $2 \times$ protein mixes, $5 \mu \mathrm{l}$ aliquots were taken at $1,2,4,8,16,32$, and $64 \mathrm{~min}$, and reactions were stopped by mixing with an equal volume of $8 \%$ SDS, $100 \mathrm{~mm}$ EDTA. ADP in the reaction aliquots was resolved from ATP by TLC and quantified using phosphor imaging plates and a Molecular Dynamics Storm imaging system as described previously (Jiang et al., 2007). Rates of ATP hydrolysis were determined by linear fits (Origin 8.5) to the data range that corresponded to $<20 \%$ hydrolysis of input ATP.

Clathrin basket dissociation assays. Clathrin baskets made from bovine brain clathrin (corresponding to a concentration of $1 \mu \mathrm{M}$ clathrin heavy and light chains or $0.3 \mu \mathrm{M}$ triskelia) were mixed with $0.1 \mu \mathrm{M}$ auxilin in 20 mm imidazole, $25 \mathrm{~mm} \mathrm{KCl}, 10 \mathrm{~mm}\left(\mathrm{NH}_{4}\right)_{2} \mathrm{SO}_{4}, 2 \mathrm{~mm} \mathrm{Mg}$ acetate, and 2 mм DTT, pH 7.0, at $25^{\circ} \mathrm{C}$. Dissociation was initiated by adding $0.3 \mu \mathrm{M}$ bovine Hsc70 preincubated with $1 \mathrm{~mm}$ ATP with or without $0.1 \mu \mathrm{M}$ Hsp110 or $2 \mu \mathrm{M}$ Bag-1 as specified in the figure legends and was monitored by dynamic light scattering using a Wyatt DynaPro (Jiang et al., 2005). NEF activity was inhibited by adding Hsc70 NBDs as indicated in the figure legends. Data were plotted using Origin and fit as described in the figure legends. To track the association of $\mathrm{Hsc} 70$ with clathrin in these reactions, dissociation was initiated with clathrin baskets, Hsc70, and auxilin with or without Hsp110 or mutant Hsp70 NBDs at the concentrations indicated in Figure 7. Immediately after mixing, $20 \mu \mathrm{l}$ of the reaction was loaded on a $400 \mu \mathrm{l}$ Superpose 6 spin column, and fractions were collected from consecutive $8 \mathrm{~s}$ spins at $500 \mathrm{rpm}$ and resolved by SDS-PAGE. Gels were imaged with a Bio-Rad Criterion Stain Free Imager and quantified with Bio-Rad Image Lab Software.

Clathrin assembly assays. Clathrin triskelia $(0.5 \mu \mathrm{M}$ final concentration) were mixed with varying concentrations of AP2 or AP180 as indicated in Figure $3 F$, and, when specified, GG/ED NBD (50 $\mu \mathrm{m}$ final) in 10 mM Tris, pH 8.0, 1 mм DTT (Morgan et al., 2003). We chose this concentration of GG/ED NBD to match the highest concentration injected for the EM studies (see below). Assembly was initiated by adding 0.1 volume of $1 \mathrm{~m}$ MES, pH 6.5, in a final volume of $200 \mu$ l, followed by incubation on ice for $45 \mathrm{~min}$ and then centrifugation at 400,000 $\times \mathrm{g}$ at 
$4^{\circ} \mathrm{C}$ for $6 \mathrm{~min}$. The upper $80 \%$ of the supernatant (unassembled fraction) was resolved by SDS-PAGE, imaged and quantified with a Bio-Rad Criterion Stain Free Imager and Image Lab Software, and the data were plotted and fit to a hyperbolic function using Origin 8.5 Software (OriginLab).

Western blot analysis. Bovine brain CCV and cytosolic fractions were prepared as described previously (Keen et al., 1979; Nandi et al., 1982). The total protein content of each fraction was determined by the Bradford method (Bio-Rad). Samples were run by SDS-PAGE along with standards as indicated and electrotransferred to PVDF membranes (GE Healthcare). The membranes were blocked with $5 \%$ nonfat dry milk (Hsc70, Bag 1, or Hsp110) or 3\% BSA (clathrin) in TBS-T (0.1\% Tween 20) for $2 \mathrm{~h}$ at room temperature (RT). Blots were incubated with the following antibodies for $1 \mathrm{~h}$ at RT: anti-Hsc70 (SPA-816, 1:5000; Stressgen), anti-Bag1 (AAM-400, 1:1000; Stressgen), anti-Hsp110 (SPA-1101, 1:2500; Stressgen), and anti-clathrin (F21-35c, 1:2000; Zhou et al., 1993), followed by three washes with TBS-T and incubation with the appropriate HRP-conjugated secondary antibody for $0.5 \mathrm{~h}$ at RT. Blots were developed with ECL plus chemoluminescent HRP substrate (GE Healthcare). Luminescence was acquired on a PharosFX imager and quantified with Quantity One software v4.6 (Bio-Rad). A standard curve was plotted from the blotted standards for each protein and the densities from the specific bands detected in the cytosolic fractions interpolated to determine the abundance of each protein. The data were analyzed by ANOVA followed by Tukey's multiple-comparisons test using Origin 8.5 software (OriginLab).

Microinjections and stimulation. Late larval stage $(10-12 \mathrm{~cm})$ lampreys (Petromyzon marinus) of either sex were anesthetized with $0.1 \mathrm{~g} / \mathrm{L}$ tricaine methanesulfonate (MS-222, Finquel; Argent Chemical Laboratories) diluted in tank water. After anesthesia was complete, a 2- to 3-cm section of spinal cord was dissected out and pinned ventral side up in a Sylgard-lined Petri dish filled with oxygenated lamprey ringer containing the following (in mM): $100 \mathrm{NaCl}, 2.1 \mathrm{KCl}, 2.6 \mathrm{CaCl}_{2}, 1.8 \mathrm{MgCl}_{2}, 4$ glucose, 0.5 glutamine, and 2 HEPES, $\mathrm{pH} 7.4$. All procedures were approved by the institutional animal care and use committee at the University of Texas at Austin and the Marine Biological Laboratory in accordance with guidelines set by the National Institutes of Health. Recombinant GG/ED $\mathrm{NBD}$ and GG/ED,RRR/EEE NBD were dialyzed overnight into lamprey internal solution containing $180 \mathrm{~mm} \mathrm{KCl}$ and $10 \mathrm{~mm}$ HEPES, pH 7.4. The proteins were then loaded into glass microelectrodes at a stock concentration of $500 \mu \mathrm{M}$ and injected directly into giant reticulospinal axons using small pulses of $\mathrm{N}_{2}$ (5-20 ms; $30-50$ psi) delivered via a Toohey Spritzer system. The giant axons make en passant synapses along their length, so axonal microinjection permits the reagents direct access to the pre-SV clusters. Lamprey internal solution was injected as a negative control. To estimate the intraaxonal concentration, all reagents were coinjected with $100 \mu \mathrm{m}$ Alexa Fluor 488 dextran $(70 \mathrm{kDa}$, anionic, lysine fixable; Invitrogen). After 15-30 min of microinjection, the intraaxonal concentration of protein reached $1 / 10$ to $1 / 20$ of that in the injection pipet. Therefore, we estimate the intraaxonal concentrations of GG/ED NBD and GG/ED,RRR/EEE NBD to be in the range of 25-50 $\mu$ M. Next, the injected axons were stimulated intracellularly by action potentials using short, depolarizing current pulses ( $1 \mathrm{~ms} ; 20-80 \mathrm{nA} ; 20 \mathrm{~Hz}, 5 \mathrm{~min}$ ) generated with an Axoclamp 2B amplifier (Molecular Devices). At the end of the stimulation period, the spinal cords were immediately fixed for EM. Fixation was complete within 5-15 s after adding fixative, as assessed by the disappearance of action potentials.

$E M$ and image analysis. Preparation of spinal cords for EM was as described previously (Morgan et al., 2004; Bourne et al., 2006; Oliphint et al., 2010). Briefly, spinal cords were fixed with $3 \%$ glutaraldehyde $/ 2 \%$ paraformaldehyde in $0.1 \mathrm{M} \mathrm{Na}$-cacodylate, $\mathrm{pH} 7.4$, for $48 \mathrm{~h}$, postfixed with $2 \%$ potassium ferrocyanide $/ 2 \%$ osmium tetroxide for $1 \mathrm{~h}$ on ice, and stained en bloc with $2 \%$ aqueous uranyl acetate for $2 \mathrm{~h}$ at room temperature. Spinal cords were then dehydrated in a graded ethanol series and embedded in Embed-812 resin. Ultrathin cross-sections (70 $\mathrm{nm}$ ) of spinal cords were cut, placed on formvar-coated grids, and counterstained with $2 \%$ uranyl acetate and lead citrate. The injected, stimulated giant reticulospinal axons were identified and all synapses within
$300 \mu \mathrm{m}$ to either side of the injection site were imaged at $26,500 \times$ magnification using a Spirit BioTwin T12 electron microscope (Technai).

Plasma membrane measurements were performed using ImageJ software as described previously (Morgan et al., 2004; Bourne et al., 2006). Briefly, a straight line $(1 \mu \mathrm{m})$ was drawn laterally from points marking the right and left edges of the active zone to the nearest points on the axonal plasma membrane. The curved distances between these points were measured, and the average for each synapse was recorded. CCVs and clathrin-coated pits (CCPs) were counted as vesicular structures surrounded by an electron-dense coat and that were either separated from or budding from the plasma membrane, respectively. For each condition (stimulation only, GG/ED NBD, and GG/ED,RRR/EEE NBD), 20-34 synapses were analyzed from two to three axons and two to three lampreys. Morphometric analyses were performed by a researcher blinded to the experimental condition. The data were analyzed by ANOVA followed by Tukey's multiple-comparisons test using Origin 8.5 software (OriginLab).

\section{Results}

\section{Construction of an Hsp70 NEF inhibitor}

The disassembly of the clathrin coat by Hsc70 may be considered analogous to reactions in which an Hsp70 chaperone, together with its co-chaperone partners, disaggregates misfolded proteins (Schlieker et al., 2002; Weibezahn et al., 2004; Weibezahn et al., 2005). In such reactions, Hsp70 is recruited to, and initially binds, its protein substrate when its nucleotide binding domain (NBD) is bound to ATP. The presence of ATP in the NBD induces an open conformation of the protein-binding domain that allows it to both rapidly release and bind protein substrates (Mayer et al., 2000). Upon ATP hydrolysis, the protein-binding domain changes to a closed conformation that stably binds its protein substrate. Spontaneous release of the protein substrate from Hsp $70^{\star} \mathrm{ADP}^{\star}$ protein substrate complexes is slow (Takeda and McKay, 1996; Theyssen et al., 1996). In vitro, many of the protein refolding/disaggregation reactions mediated by Hsp70s are enhanced by co-chaperones that function as NEFs and stimulate the release of ADP from the Hsp70, allowing ATP to bind so that protein substrates can be both released and rebound (Schröder et al., 1993; Szabo et al., 1994; Gässler et al., 2001; Brehmer et al., 2004; Polier et al., 2008).

The known eukaryotic Hsp70 NEFs include the Bag1-5 proteins, HspBP1, and Hsp110. Although these NEFs are structurally distinct, they all share certain mechanistic features, which we took advantage of to create a NEF inhibitor. First, Hsp70 NEFs interact primarily, if not exclusively, with the NBD of the Hsp70 (Fig. 2A; Harrison et al., 1997; Sondermann et al., 2001; Shomura et al., 2005; Polier et al., 2008; Schuermann et al., 2008; Xu et al., 2008). Second, these interactions are stable: complexes of NEFs with Hsp70 NBDs (in either nucleotide-free or ADP states) can be isolated and crystallized (Polier et al., 2008; Schuermann et al., 2008). The mirror symmetric interaction of Hsp70 with Hsp110, which is itself a member of the Hsp70 family, is especially stable. The Hsp70:Hsp110 complex buries $16,000 \AA^{2}$ of protein surface and includes 68 salt bridge or direct $\mathrm{H}$-bonds between the two proteins (Schuermann et al., 2008). Third, dissociation of these complexes occurs when ATP binds to the Hsp70 NBD and induces a conformational change that ruptures the interaction with the NEF (Fig. 2A; Raviol et al., 2006). These observations indicate that an Hsp70 NBD that cannot bind ATP will be a potent NEF inhibitor, since it will form a persistent interaction with the NEF that cannot be dissociated by ATP. Because such an NBD will not bind or hydrolyze ATP and because it lacks the Hsp70 proteinbinding domain, concern that the in vivo effects of such an inhibitor may be due to local perturbation of ATP pools or interactions 
between the protein-binding domain and other proteins is eliminated.

To engineer such a NEF inhibitor, we mutated glycines 201 and 202 of bovine Hsc70 NBD (residues 1-386) to glutamate and aspartate, respectively, and designated this mutant as GG/ED NBD. These glycines contact the phosphates of bound ATP and the introduction of large, negatively charged side chains at these positions disrupts ATP binding through both steric and electrostatic effects (Fig. 2B; Flaherty et al., 1994). To determine whether the GG/ED NBD would inhibit NEF activity, we tested its ability to inhibit Hsp110 stimulation of ATP hydrolysis by Hsc70 (Fig. 2C). For these experiments, we used a mutant Hsc70 (D152K), the auxilin-stimulated rate of ATP hydrolysis of which is so high that the limiting step in multiple turnover ATP hydrolysis is the rate at which the ADP is released from Hsc70 (Jiang et al., 2005; Jiang et al., 2007). When yeast Hsp 110 was added to reactions with this mutant $\mathrm{Hsc70}$ and auxilin, it increased the rate of ATP hydrolysis fourfold (Fig. 2C, compare columns 1, 2) because the Hsp110stimulated ADP release from the Hsc70. We then tested the effects of adding wildtype (WT) Hsc70 NBD to reactions with the mutant Hsc70, auxilin, and yeast Hsp110. ATP-bound NBD will not bind Hsp110 (Dragovic et al., 2006) and, because WT NBD has a very low ATPase rate and is effectively saturated with ATP at the concentrations used in these reactions, it should not bind Hsp110 or inhibit Hsp110 stimulation of ADP release from Hsc70. Consistent with this, the addition of WT NBD had no effect on the rate of ATP hydrolysis (Fig. 2C, compare columns 2, 3). We then tested the effect of adding the GG/ED NBD to these reactions. Because the GG/ED NBD cannot bind ATP, it is expected to bind Hsp 110 and block its ability to stimulate ADP release from Hsc70. Indeed, addition of the GG/ED NBD almost completely eliminated the ATP-hydrolysisstimulating effect of Hsp110 on the Hsc70 (Fig. 2C, compare columns 3, 4). Control experiments revealed that WT NBD and Hsp1 10 together had $<5 \%$ the ATPase rate of the D152K Hsc70/ auxilin/Hsp110 reaction (Fig. 2C, column 5). Likewise, the GG/ED NBD and Hsp110 together had an even lower rate (Fig. $2 C$, column 6), which is consistent with our expectation that the GG/ED mutation disrupts ATP hydrolysis by the NBD. These data indicate that the GG/ED NBD acts as an effective inhibitor of Hsp110 stimulation of Hsc70 ATPase activity.

Because the GG/ED NBD inhibited Hsp110 function in the ATPase assays, we predicted that it would also inhibit the effects of Hsp110 and other NEFs on clathrin uncoating. We tested this by using clathrin basket disassembly, as monitored by dynamic light scattering (Schuermann et al., 2008). In such reactions, we

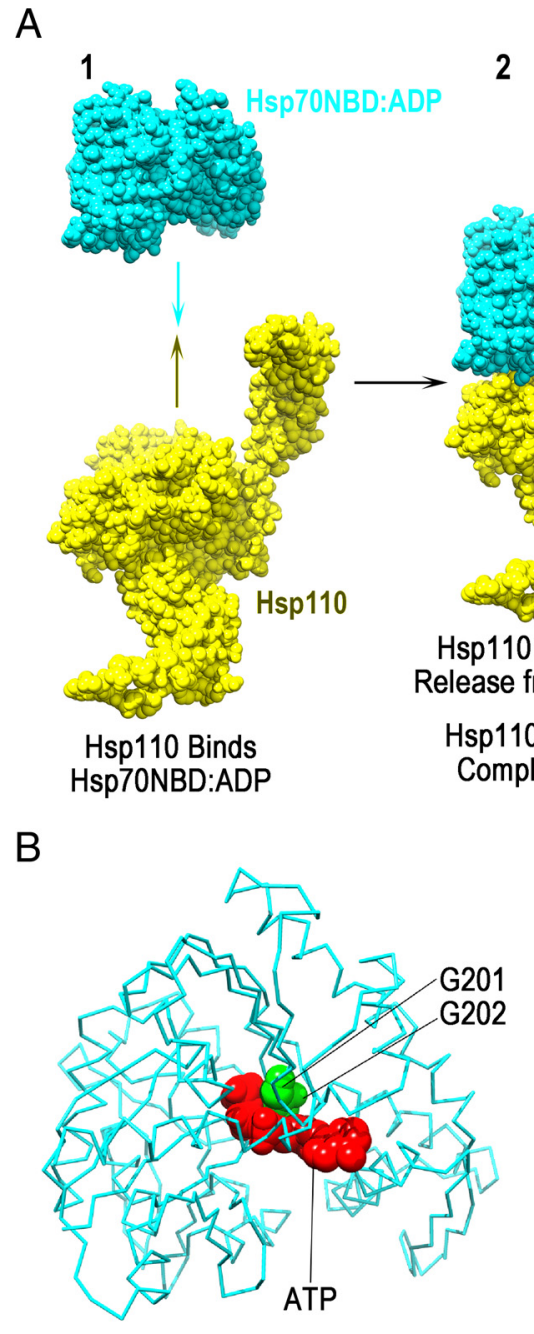

2
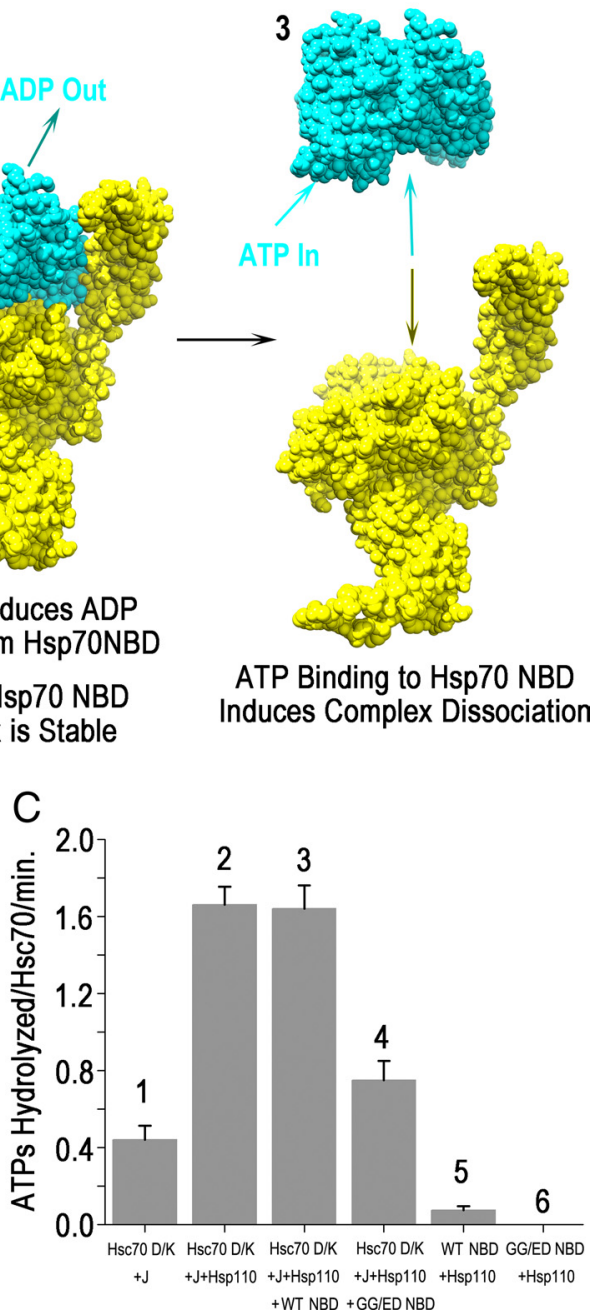

Figure 2. An ATP-binding-deficient Hsc70 NBD inhibits Hsp110 stimulation of Hsc70 ATPase activity. A, Rationale for construction of an Hsp70 NEF inhibitor: (1) NEFs such as Hsp110 (shown in space-filling representation in yellow) bind the Hsp70 NBD (cyan) when the latter is nucleotide free or bound to ADP. (2) The interaction between Hsp110 and the Hsp70 NBD induces the latter to 列 (Flaherty et al., 1994) is shown with bound ATP(red) and residues G201/G2 auxilin + yeast Hsp110; (3) Hsc70D152K + auxilin + yeast Hsp110 + WT NBD; (4) Hsc70D152K + auxilin + yeast Hsp110 + GG/ED NBD; (5) yeast Hsp110 + WT NBD; and (6) yeast Hsp110 + GG/ED NBD. In these experiments, yeast Hsp110 was used instead of mammalian Hsp110 because it has a lower ATPase rate. Human Hsp110 was used for all subsequent experiments.

use clathrin baskets, which are similar to the coats that surround vesicles in vivo. The addition of ATP, auxilin, and Hsc70 at onethird the concentration of clathrin heavy chains in the reaction resulted in a clearly biphasic drop in light scattering, with onethird of the decrease occurring rapidly and the remaining twothirds decreasing slowly (Fig. $3 A, C$, red circles). The first phase of these burst kinetics corresponds to disassembly of approximately one-third of the clathrin baskets by the added Hsc70, followed by a slower phase limited by the rate at which $\mathrm{Hsc} 70$ is released from the depolymerized clathrin (Schuermann et al., 2008). When 0.1 $\mu \mathrm{M}$ Hsp110 was added, the second phase was accelerated to the point where it was no longer clearly distinguishable from the first phase and all of the baskets were rapidly depolymerized (Fig. 3A, green circles). Although Hsp110 itself has chaperone activity and could potentially contribute directly to clathrin disassembly, the 
A

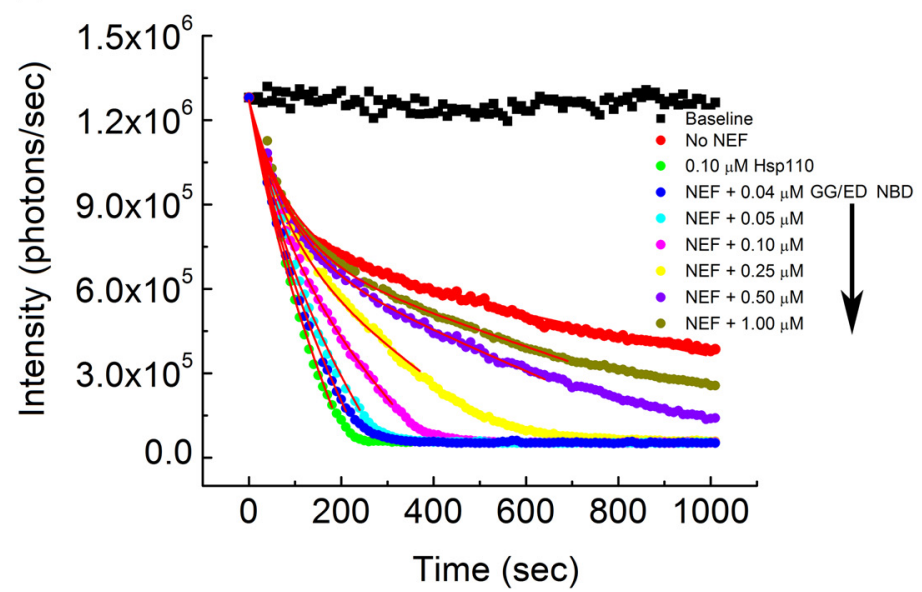

C

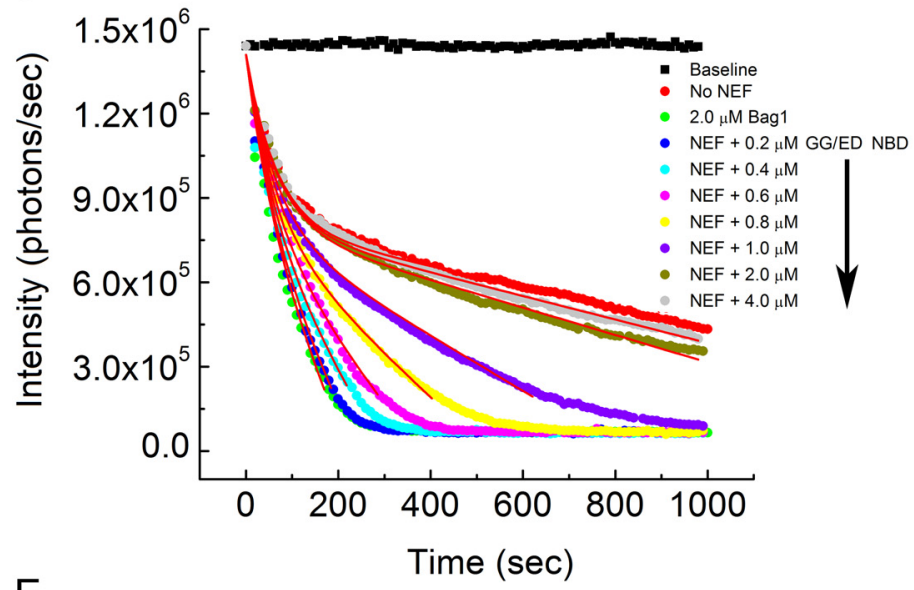

E

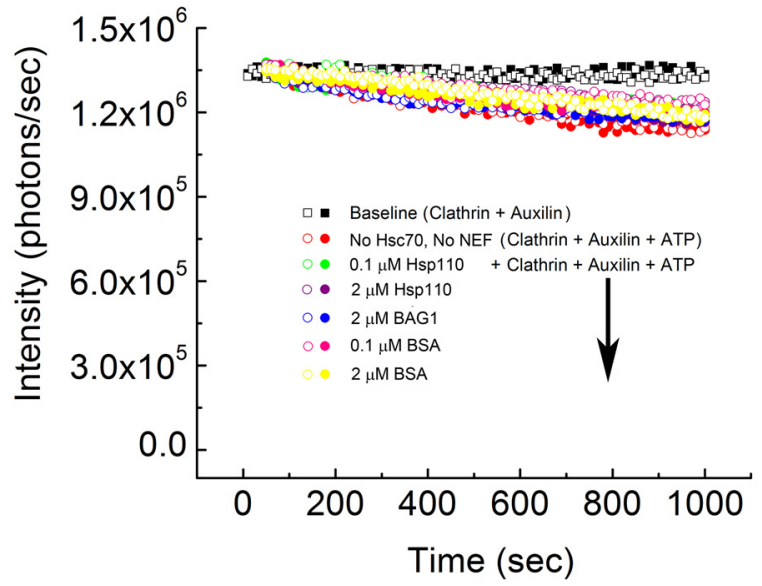

B

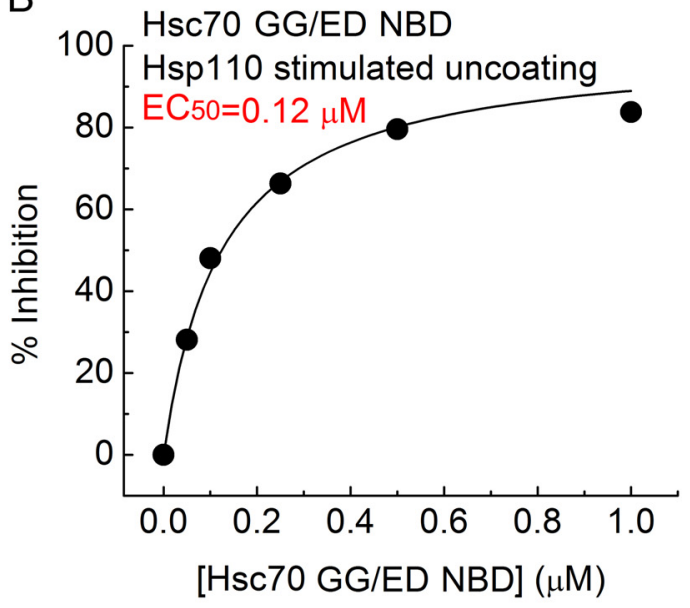

D

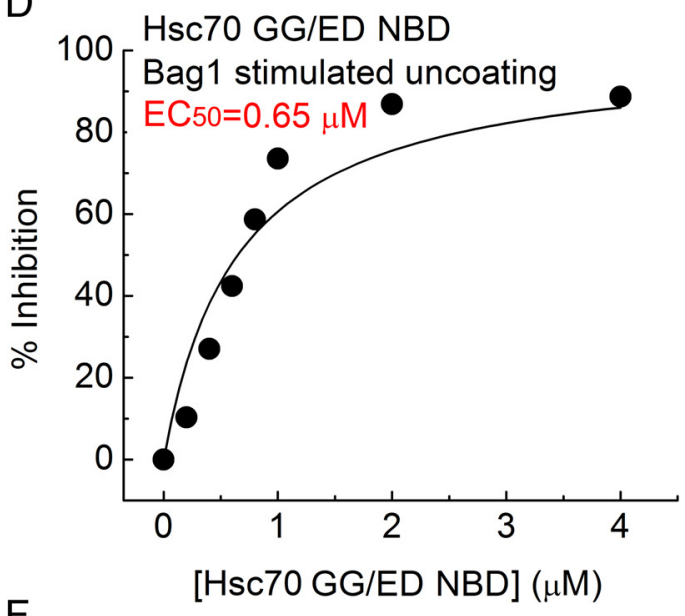

$\mathrm{F}$

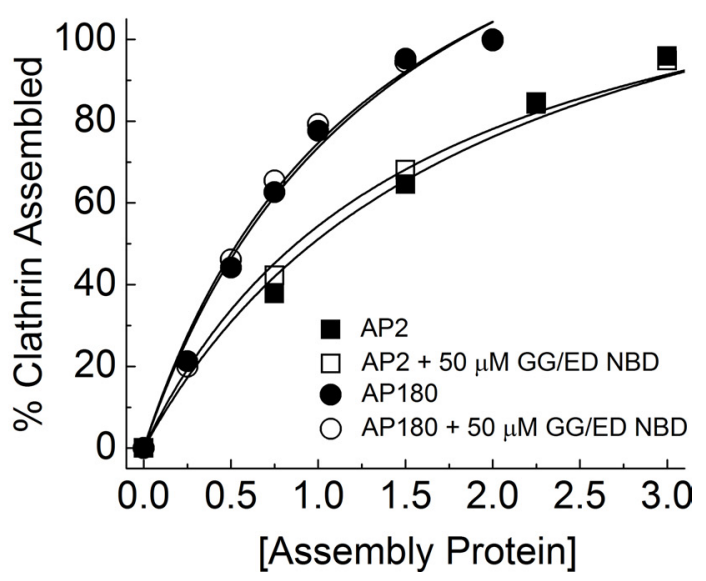

Figure 3. An ATP-binding-deficient Hsc70 NBD inhibits NEF stimulation of clathrin basket disassembly. A, Clathrin coat disassembly as monitored by dynamic light scattering. Disassembly reactions contained clathrin baskets and auxilin only (black squares); clathrin baskets with ATP, auxilin, and Hsc70 (red circles); clathrin + ATP + auxilin + Hsc70 + Hsp110 (green circles); or clathrin + ATP + auxilin + Hsc70 + Hsp110 and varying amounts of GG/ED NBD (0.04 $\mu \mathrm{m}$ : blue circles; $0.05 \mu \mathrm{m}$ : cyan circles; $0.1 \mu \mathrm{m}$ : magenta circles; $0.25 \mu \mathrm{m}:$ yellow circles; $0.5 \mu \mathrm{m}$ : purple circles; $1.0 \mu \mathrm{m}$ : olive circles). Data are globally fit to $y=y_{0}+A^{*}\left(\exp \left(-t_{1}{ }^{*} x\right)-1\right)-k^{*} x$, where $y_{0}$ is the photons scattered at $x=0 \mathrm{~s}(\sim 1,275,000$ for $1 \mu \mathrm{m}$ clathrin), $A$ is the amplitude of first (rapid) exponential phase, $t_{1}$ is the time constant of first exponential phase, $k$ is the rate of second (slow) linear phase (the decrease/second in the number of scattered photons). Data were globally fit with the $y_{0}$ value held constant because this value is determined by the (constant) amount of clathrin baskets added to each reaction and with $A$ and $t_{1}$ shared since the kinetic scheme has $A$ and $t_{1}$ determined by the constant amount of $\mathrm{Hsc} 70$ present in all reactions. $\boldsymbol{B}$, Percentage inhibition of Hsp 110 stimulation of uncoating in $\boldsymbol{A}$ plotted as a function of the GG/ED NBD concentration. $\boldsymbol{C}$, As in $A$, but using Bag1 at $2.0 \mu \mathrm{m}$ instead of Hsp110 at $0.1 \mu \mathrm{m}$, and with the GG/ED NBD at $0.2 \mu \mathrm{m}$ (blue circles), $0.4 \mu \mathrm{m}$ (cyan circles), $0.6 \mu \mathrm{m}$ (magenta circles), $0.8 \mu \mathrm{m}$ (yellow circles), $1.0 \mu \mathrm{m}$ (purple circles), $2.0 \mu \mathrm{m}$ (olive circles), or $4.0 \mu \mathrm{m}$ (gray circles). $\boldsymbol{D}$, As in $\boldsymbol{B}$, but with data from ( plotted. $\boldsymbol{E}$, NEFs cannot promote coat disassembly in the absence of Hsc70. Disassembly reactions contained clathrin baskets and auxilin only (black squares), or clathrin baskets with auxilin and ATP (red circles), or clathrin + auxilin + ATP + varying amounts of NEFs or control proteins: $0.1 \mu \mathrm{m} \mathrm{Hsp110}$ (green), $2 \mu \mathrm{m} \mathrm{Hsp110} \mathrm{(purple),} 2 \mu \mathrm{m} \mathrm{Bag1}$ (blue), $0.1 \mu \mathrm{mBSA}$ (magenta), or $2 \mu \mathrm{m} \mathrm{BSA} \mathrm{(yellow).} \mathrm{Although} \mathrm{a} \mathrm{very} \mathrm{slight} \mathrm{decrease} \mathrm{in} \mathrm{scattering} \mathrm{intensity} \mathrm{was} \mathrm{observed} \mathrm{when} \mathrm{ATP} \mathrm{was} \mathrm{added} \mathrm{to} \mathrm{clathrin}$ baskets and auxilin, no further decrease in scattering intensity was observed when any of the NEFs or control proteins was added in the absence of Hsc70. F, The GG/ED NBD has no effect on clathrin assembly. Clathrin was induced to assemble by AP2 (squares) or AP180 (circles) at pH 6.5 in the absence (solid symbols) or presence (open symbols) of $50 \mu \mathrm{M}$ GG/ED NBD. The addition of GG/ED NBD had no effect on either AP2- or AP180-mediated coat assembly. 

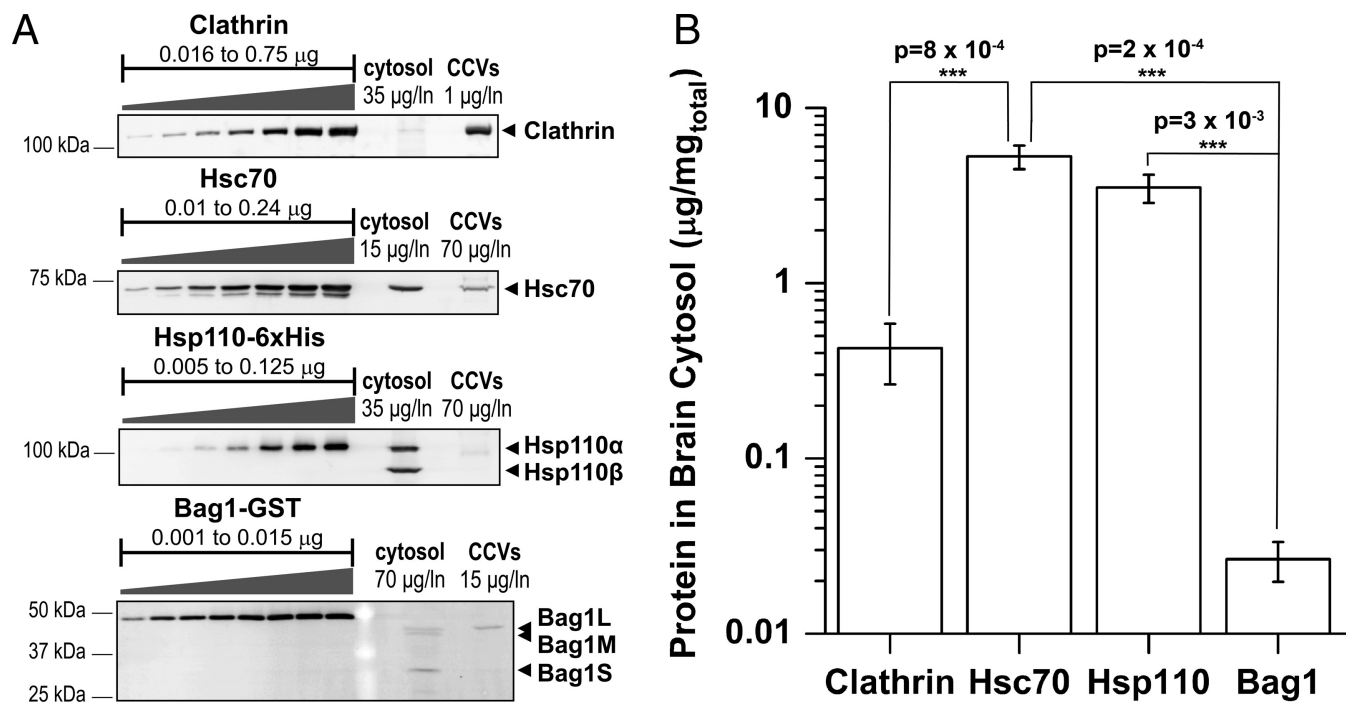

Figure 4. Hsc70 is in large excess of clathrin in brain cytosol. $A$, Quantitative Western blots were performed to determine the content of clathrin, Hsc70, Hsp 110, or Bag1 in bovine brain cytosol in the presence of calibrated standards of each protein, as well as a purified CCV control enriched in clathrin (Pearse, 1975; Blondeau et al., 2004). Note that there are two isoforms of Hsp110 (Ishihara et al., 1999) and three isoforms of Bag1 (Cutress et al., 2003). Bands were quantified separately by densitometry and summed for each protein in the analysis shown in $\boldsymbol{B}$. $\boldsymbol{B}$, Quantitative analysis of clathrin, Hsc70, Hsp110, and Bag 1 in brain cytosol. The bars represent the mean of the respective protein amounts in micrograms/milligram of total protein \pm SEM from 5 to 13 independent experiments. Asterisks indicate statistical significance using ANOVA.

addition of Hsp110, auxilin, and ATP to baskets without Hsc70 caused negligible uncoating (Fig. 3E). Hsp110 stimulation of basket disassembly in reactions with Hsc70 is therefore attributed to the NEF action of Hsp110 on Hsc70. When increasing amounts of the GG/ED NBD were added to these reactions, the stimulating effect of Hsp110 on disassembly was suppressed (Fig. 3A, blue through olive circles). The $\mathrm{EC}_{50}$ value for GG/ED NBD inhibition of Hsp110-mediated stimulation of disassembly was $0.12 \mu \mathrm{M}$ (Fig. 3B). Experiments performed with another NEF, Bag1, revealed that the GG/ED NBD also inhibited Bag1-mediated stimulation of clathrin basket disassembly, but with an $\mathrm{EC}_{50}$ value of $0.65 \mu \mathrm{M}$ (Fig. $3 C, D$ ). Higher concentrations of NEF and GG/ED NBD were used in the Bag1 versus Hsp110 experiments, because Bag1 requires higher concentrations to drive the same acceleration of uncoating as Hsp110 (Schuermann et al., 2008). The GG/ED NBD does not inhibit the rate or amplitude of the initial NEF-independent phase of basket disassembly, nor does it slow the second phase to a rate that is less than seen in the absence of NEF. The inhibitory effects of the GG/ED NBD are therefore specific to the NEF and do not affect the intrinsic activity of auxilin or Hsc70 in basket disassembly. The ATP hydrolysis and clathrin disassembly data indicate that the GG/ED NBD is an effective inhibitor of the Hsp110 and Bag1 NEFs.

We also investigated whether the inhibitory GG/ED NBD had any effect on clathrin basket assembly mediated by assembly proteins AP180 or AP2. These are proteins that recruit clathrin to endocytic sites and promote its polymerization (Ahle and Ungewickell, 1986; Keen, 1987; González-Gaitán and Jackle, 1997; Hao et al., 1997; Zhang et al., 1998; Morgan et al., 2000; Ford et al., 2001). We measured the amount of clathrin that assembles into baskets in the presence of varying amounts of either of these assembly proteins and with or without $50 \mu \mathrm{M}$ GG/ED NBD. As seen in Figure 3F, the GG/ED NBD had no effect on AP2- or AP180-mediated basket assembly.

\section{Hsc70 is present in large excess of clathrin in brain cytosol} The expected effect of a NEF inhibitor on SV recycling depends on whether clathrin is in excess of Hsc70 in neuronal cytosol or if
Hsc70 is in excess of clathrin. If clathrin is in excess of Hsc70 (Fig. $1 B$ ), then inhibition of NEF activity would leave some clathrin free and available for endocytosis, but would cause most $\mathrm{Hsc} 70$ to become sequestered in clathrin ${ }^{\star} \mathrm{Hsc} 70^{\star} \mathrm{ADP}$ complexes and be unavailable for uncoating. We would therefore expect to see an increase in CCV number but not an inhibition of vesicle endocytosis from the plasma membrane. Conversely, if $\mathrm{Hsc70}$ is present in excess of clathrin (Fig. 1C), inhibition of NEF activity should leave some Hsc70 free and available for uncoating, but would cause most clathrin to be sequestered in clathrin ${ }^{\star} \mathrm{Hsc} 70^{\star} \mathrm{ADP}$ complexes and unavailable for endocytosis. This would result in an inhibition of endocytosis and a consequent increase in plasma membrane surface area, but not an increase in CCV number.

We used quantitative Western blots to determine the amount of clathrin, Hsc70, Hsp110, and Bag1 in brain cytosol. We found that Hsc70 is $\sim 10$-fold more abundant than clathrin in brain cytosol (Fig. 4). This is consistent with Hsc70's proposed function in chaperoning depolymerized clathrin and implies that stabilization of clathrin ${ }^{\star} \mathrm{Hsc} 70^{\star} \mathrm{ADP}$ complexes will result in depletion of free clathrin but not of Hsc70. We also found that Hsp110 is highly abundant in brain cytosol, being present at nearly the same levels as Hsc70 and $\sim 100$-fold more abundant than Bag1 (Fig. 4).

\section{Mutations that disrupt NBD interactions with Hsp110 specifically abolish the effect of the GG/ED NBD on Hsp110 activity}

The observation that Hsp110 is as abundant as Hsc70 in brain cytosol and is $\sim 100$-fold more abundant than Bag1 suggests that Hsp 110 could be the physiologically relevant NEF during SV recycling. To investigate this, we generated an inhibitor that would inhibit other NEFs, but not Hsp110. Structures have been solved for complexes between Hsp70 NBDs and all classes of known Hsp70 NEFs (Harrison et al., 1997; Sondermann et al., 2001; Shomura et al., 2005; Jiang et al., 2007; Polier et al., 2008; Schuermann et al., 2008; Xu et al., 2008). For many of these NEFs (Bag1, BNB, HspBp1), the binding sites on the Hsp70 NBD are at least partially overlapping, but Hsp110 is unique in using a long 

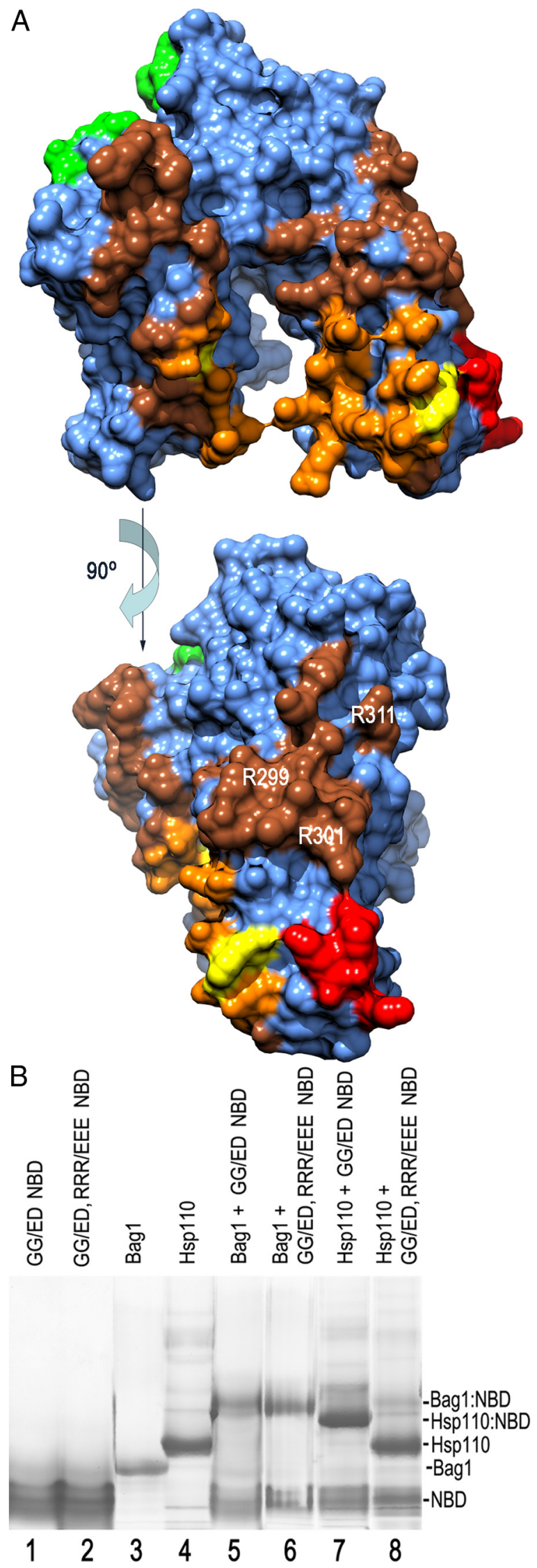

Figure 5. Mutations in the $\mathrm{Hsc70}$ region that interacts specifically with $\mathrm{Hsp} 110$ specifically disrupt binding to Hsp 110. $A$, Surface representations of the Hsc70 NBD with different regions of the surface colored according to whether they interact with Bag1/Bag5 (orange; Sondermann helical arm to make ionic interactions with the electropositive surface of lobe IIB of the Hsc70 NBD, a segment that encompasses bovine Hsc70 residues 299-311 (Fig. 5A). Mutations in this region should disrupt interaction with Hsp110, but not with other NEFs. We constructed an R299/R301/R311 $\rightarrow$ EEE triple substitution in the GG/ED background (GG/ED,RRR/EEE) to generate repulsion between this part of the Hsc70 surface and the electronegative region of Hsp110 that interacts with it. Native PAGE was used to determine whether the mutation affected interaction with Hsp110 (Fig. 5B). When either excess GG/ED NBD or GG/ED,RRR/EEE NBD was mixed with Bag1, we observed the disappearance of the Bag1 band and the appearance of a more slowly migrating species corresponding to a Bag1:NBD complex (Fig. 5B, compare lane 3, lanes 5 and 6). When Hsp110 was mixed with the GG/ED NBD, we similarly observed the disappearance of the Hsp110 band and the appearance of a more slowly migrating species corresponding to the Hsp110:NBD complex (Fig. 5B, compare lane 7, lane 4). However, when Hsp110 was mixed with the GG/ED,RRR/EEE NBD, the Hsp110 band did not shift and no new band corresponding to an Hsp110: NBD complex was seen (Fig. 5B, compare lanes 7, 8). This indicates that the RRR/EEE mutation disrupts interaction with Hsp110, but not Bag1.

The GG/ED NBD is presumed to inhibit Hsp110 stimulation of Hsc70-mediated basket disassembly by binding directly to Hsp110. Because the GG/ED, RRR/EEE NBD binds Hsp110 poorly or not at all, it should also show reduced inhibition of Hsp110 stimulation of basket disassembly. To investigate this, we ran experiments like those shown in Figure 3, but using the GG/ ED,RRR/EEE NBD as the inhibitor. Inhibition of Bag1 by the GG/ED,RRR/EEE NBD ( $\mathrm{EC}_{50}$ value of $0.71 \mu \mathrm{M}$; Fig. $6 C, D$ ) was essentially indistinguishable from that by the GG/ED NBD $\left(\mathrm{EC}_{50}\right.$ value of $0.65 \mu \mathrm{M}$; Fig. $3 C, D$ ). In contrast, the GG/ED,RRR/EEE NBD was much less effective at inhibiting Hsp110. For the GG/ $\mathrm{ED}, \mathrm{RRR} / \mathrm{EEE} \mathrm{NBD}$, the $\mathrm{EC}_{50}$ value for inhibition of Hsp 110 was $176 \mu \mathrm{M}$ (Fig. $6 A, B$ ), or $\sim 1500$-fold greater than the $0.12 \mu \mathrm{M} \mathrm{EC}_{50}$ value for the GG/ED NBD (Fig. $3 A, B$ ). The RRR/EEE triple substitution therefore renders the GG/ED NBD specifically deficient in binding to and inhibiting Hsp110 activities in vitro.

Our hypothesis is that the GG/ED NBD inhibits Hsp110 stimulation of basket disassembly because the GG/ED NBD binds Hsp 110 and blocks its ability to induce Hsc70:clathrin dissociation. To test this directly, we used rapid gel exclusion chromatography to track the fate of $\mathrm{Hsc70}$ in clathrin basket disassembly reactions. When these reactions were performed without Hsp110, we observed most of Hsc70 co-eluting with the $650 \mathrm{kDa}$ clathrin triskelia (Fig. 7A), indicating that these proteins were associated with each other. When Hsp110 was present, most of the Hsc70 eluted later, at a position consistent with its $70 \mathrm{kDa}$ molecular weight (Fig. $7 B$ ), revealing that Hsp110 disrupted the Hsc70* clathrin interaction. When excess GG/ED NBD was then added to these reactions, most of the Hsc70 shifted back to coeluting with clathrin (Fig. $7 C$ ), showing that the GG/ED NBD

et al., 2001; Arakawa et al., 2010), Bag2/BNB (yellow; Xu et al., 2008), HspBp1 (red; Shomura et al., 2005), auxilin J domain (green; Jiang et al., 2007), or Hsp110 (brown; Polier et al., 2008, Schuermann et al., 2008). There is some overlap between the regions contacted by the different c0-chaperones, but the region encompassing residues $R 299-R 311$ is not known to interact with any co-chaperone except Hsp110. $\boldsymbol{B}$, Native gel electrophoresis of the indicated proteins. Lane 1:Hsc70 GG/ED NBD;lane 2:GG/ED RRR/EEENBD;lane3:Bag1;lane 4:Hsp110;lane 5: Bag1 + GG/ED NBD; lane 6: Bag1 + GG/ED RRR/EEE NBD; lane 7: Hsp110 + GG/ED NBD; lane 8: Hsp110 + GG/ED RRR/EEE NBD. 
A

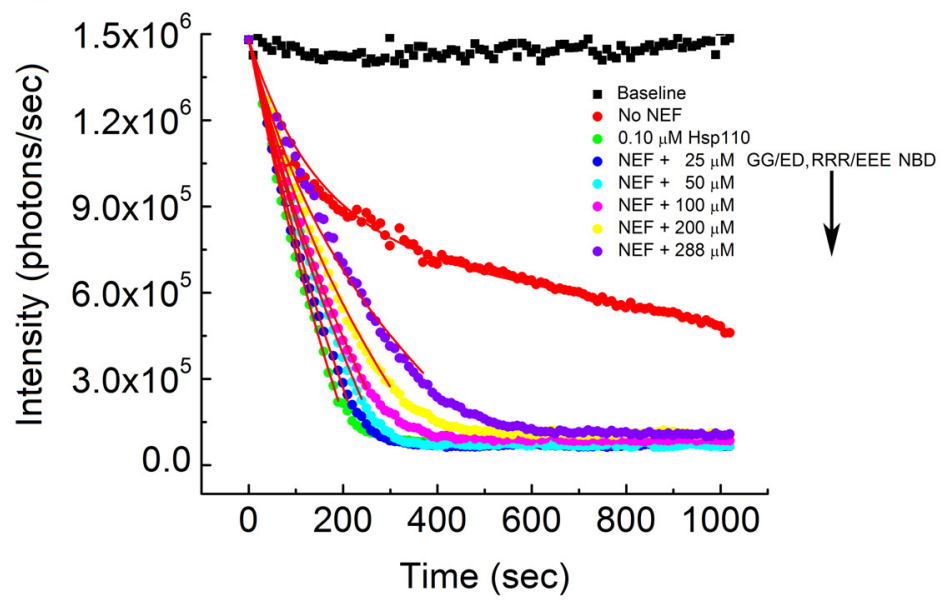

C

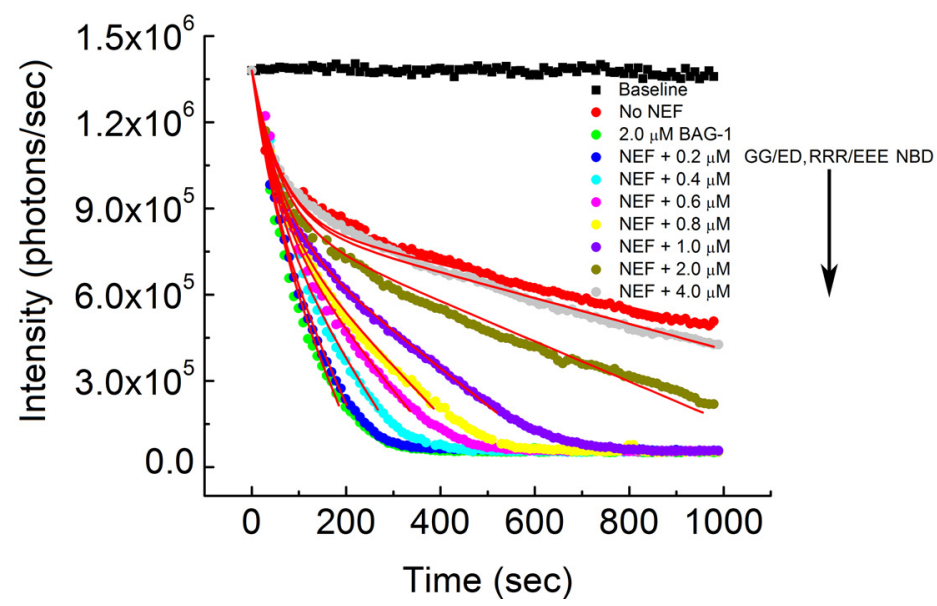

B

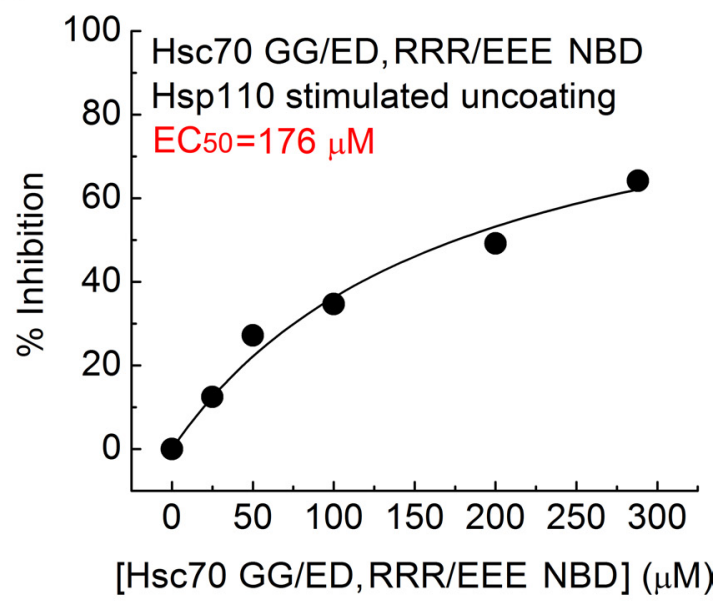

D

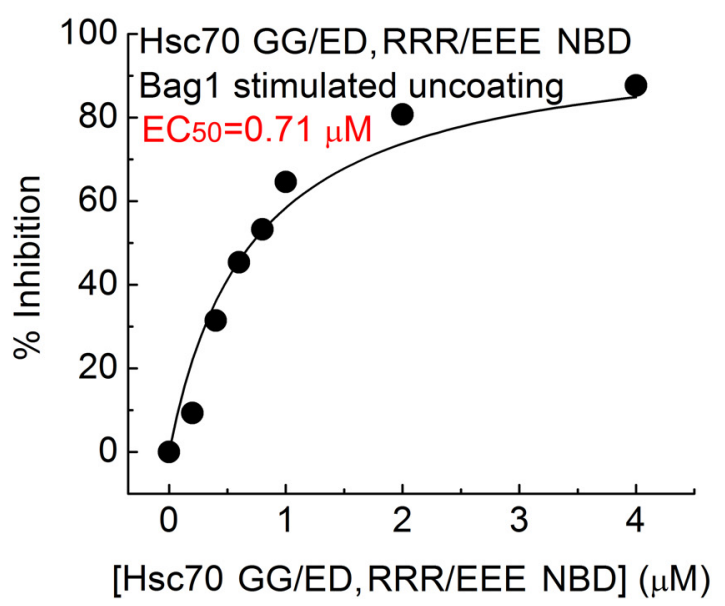

Figure 6. An ATP-and Hsp110-binding deficient Hsc70 NBD inhibits Bag1 but not Hsp110.A, Clathrin coat disassembly as monitored by dynamic light scattering. Disassembly reactions contained clathrin baskets and auxilin only (black squares), or clathrin baskets with ATP, auxilin, and Hsc70 (red circles); clathrin + ATP + auxilin + Hsc70 + Hsp110 (green circles); or clathrin + ATP + auxilin + Hsc70 + Hsp110 and varying amounts of GG/ED,RRR/EEE NBD (25 $\mu \mathrm{m}$ : blue circles; $50 \mu \mathrm{m}$ : cyan circles; $100 \mu \mathrm{m}$ : magenta circles; $200 \mu \mathrm{m}$ : yellow circles; $280 \mu \mathrm{m}$ : purple circles. $\boldsymbol{B}$, Percentage inhibition of $\mathrm{Hsp} 110$ stimulation of uncoating in $\boldsymbol{A}$ plotted as a function of the GG/ED,RRR/EEE NBD concentration. $\boldsymbol{C}$, As in $\boldsymbol{A}$, but using Bag1 at $2.0 \mu \mathrm{m}$ instead of Hsp110 at $0.1 \mu \mathrm{M}$, and with the GG/ED,RRR/EEE NBD at $0.2 \mu \mathrm{m}$ (blue circles), $0.4 \mu \mathrm{m}$ (cyan circles), $0.6 \mu \mathrm{m}$ (magenta circles), $0.8 \mu \mathrm{m}$ (yellow circles), $1.0 \mu \mathrm{m}$ (purple circles), $2.0 \mu \mathrm{m}$ (olive circles), or $4.0 \mu \mathrm{m}$ (gray circles). $\boldsymbol{D}$, As in $\boldsymbol{B}$, but with data from $\boldsymbol{C}$ plotted. Data were fit as described in the legend to Figure 3.

blocked the ability of Hsp110 to disrupt clathrin:Hsc70 interactions. In the presence of the GG/ED, RRR/EEE NBD, however, most of the Hsc70 continued to elute separate from clathrin (Fig. $7 D$ ), indicating that this mutant cannot inhibit Hsp110 disruption of $\mathrm{Hsc} 70^{\star}$ clathrin interactions.

SV endocytosis at the lamprey reticulospinal synapse is inhibited by the GG/ED NBD, but not by the GG/ED,RRR/ EEE NBD

Our efforts generated two inhibitors of Hsp70 NEF activity, neither of which should affect ATP pools nor interact with protein substrates. The GG/ED NBD should sequester and inhibit the ability of all Hsp70 NEFs (and potentially other Hsp70 NBDbinding proteins) to disrupt $\mathrm{Hsc} 70^{\star}$ clathrin interactions, whereas the GG/ED,RRR/EEE NBD should inhibit all NEFs except $\mathrm{Hsp} 110$. We used giant reticulospinal synapses of lamprey to test the effects of these inhibitors on SV endocytosis in vivo. This model vertebrate synapse is accessible via axonal microinjection, and therefore injection of specific inhibitors permits acute perturbation of any molecule of choice at presynapses. Indeed, the lamprey giant reticulospinal synapse has been used to elucidate many aspects of presynaptic function, including the mechanisms of clathrin-mediated SV recycling (Pieribone et al., 1995; Shupliakov et al., 1997; Ringstad et al., 1999; Morgan et al., 2004; Brodin and Shupliakov, 2006; Sundborger et al., 2011; von Kleist et al., 2011). If a NEF is involved in dissociating clathrin ${ }^{\star} \mathrm{Hsc}{ }^{\star}{ }^{\star}$ ADP complexes at presynapses, then the introduction of the GG/ED NBD to synapses should sequester the NEF and inhibit this dissociation. Because there is at least 10 -fold more Hsc70 than clathrin in brain cytosol (Fig. 4), stabilization of clathrin ${ }^{\star} H s c 70^{\star} \mathrm{ADP}$ complexes should reduce the clathrin available for endocytosis without markedly reducing the free Hsc70 available for uncoating or other Hsc70-mediated processes. In previous studies, when reagents that bind clathrin and inhibit early stages of clathrin-mediated endocytosis were acutely injected into nerve terminals, an increase in plasma membrane area was seen because exocytosed SV could not be retrieved efficiently (Morgan et al., 1999; Morgan et al., 2000; von Kleist et al., 2011). Therefore, if NEFs are involved in releasing clathrin from Hsc70 during SV endocytosis, the prediction is that GG/ED NBD should inhibit SV endocytosis and cause an increase in plasma membrane area (Fig. 1C).

To investigate this, lamprey giant reticulospinal axons were microinjected with Hsc70 GG/ED NBD and stimulated $(20 \mathrm{~Hz}, 5$ $\mathrm{min}$ ) to induce SV exocytosis and endocytosis, and then fixed and 
A

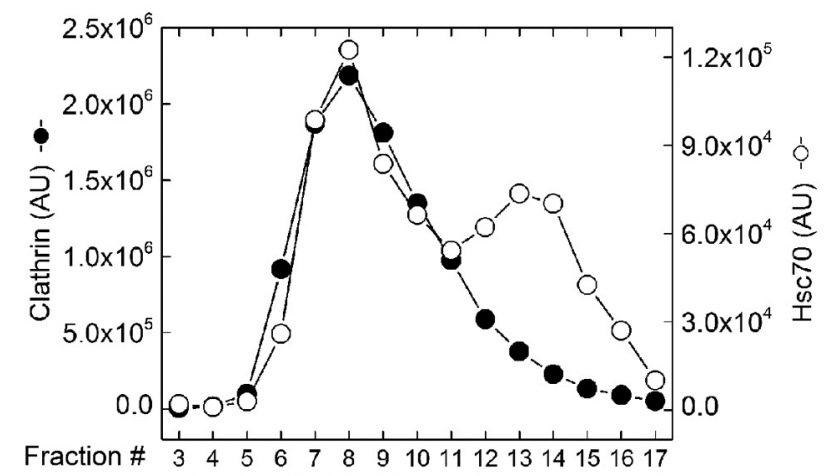

$-\infty \operatorname{bec}-\infty-\ldots$

$<$ Clathrin

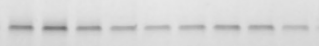

$<\mathrm{Hsc} 70$

C
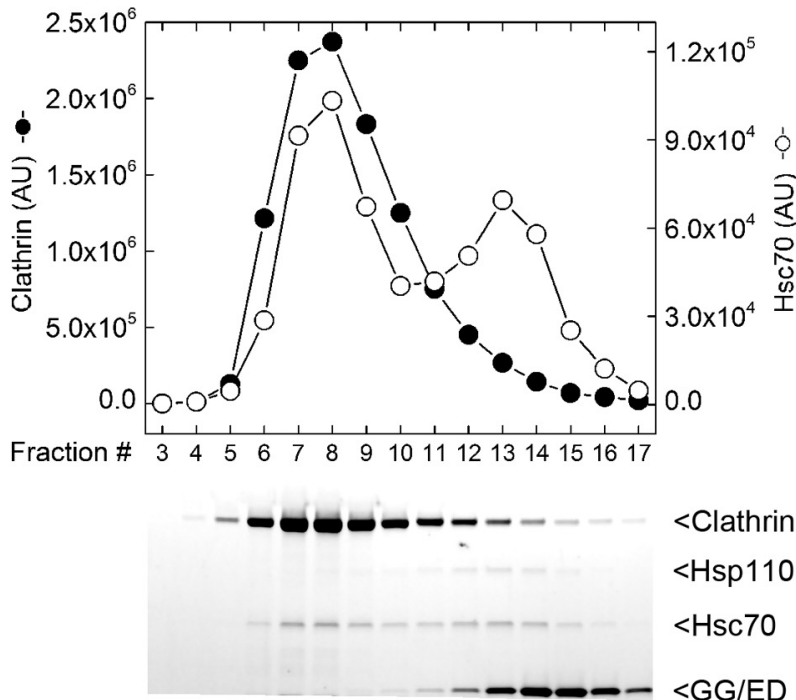

$<$ Clathrin

$<$ Hsp110

$<\mathrm{Hsc} 70$

$<$ GG/ED NBD
B

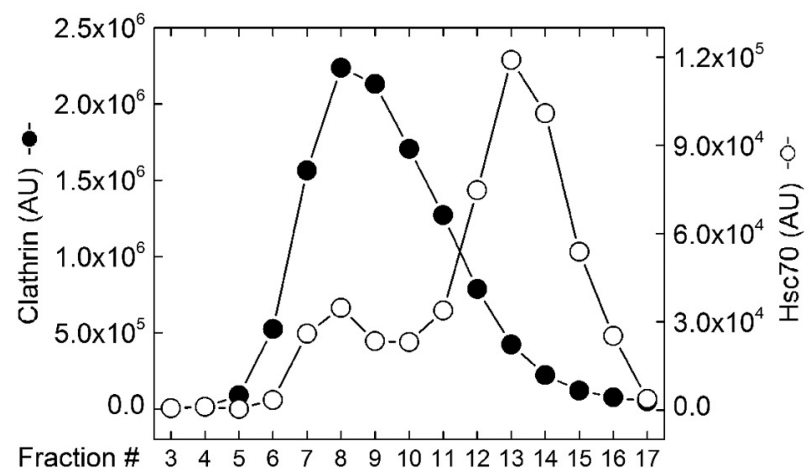

$<$ Clathrin

$<$ Hsp110

$<\mathrm{Hsc} 70$

D
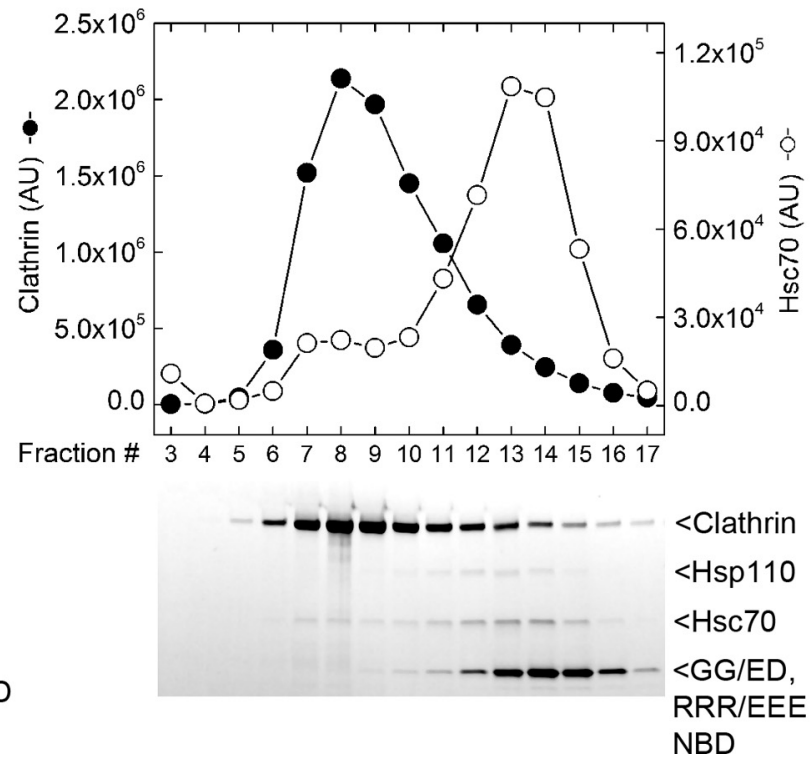

Figure 7. GG/ED NBD inhibits the ability of Hsp110 to disrupt Hsp70:clathrin interactions. A, Quantitative analysis (top; filled circles: clathrin; empty circles: Hsc70) of SDS PAGE (bottom) of basket

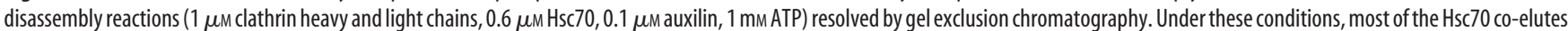
with clathrin. $B$, As in $A$, but with $0.1 \mu \mathrm{m} H s p 110$ added. Under these conditions, most of the $\mathrm{Hsc} 70$ elutes at a position later than clathrin because Hsp 110 promotes its dissociation from the clathrin. C, As in B, but with $4 \mu \mathrm{m} \mathrm{GG/ED} \mathrm{NBD} \mathrm{added.} \mathrm{Now,} \mathrm{most} \mathrm{of} \mathrm{the} \mathrm{Hsc70} \mathrm{co-elutes} \mathrm{with} \mathrm{clathrin,} \mathrm{again,} \mathrm{because} \mathrm{Hsp110} \mathrm{is} \mathrm{being} \mathrm{sequestered} \mathrm{by} \mathrm{the} \mathrm{GG/ED} \mathrm{NBD.} \mathrm{D,} \mathrm{As} \mathrm{in} \boldsymbol{B}$ but with $4 \mu \mathrm{m} \mathrm{GG/ED,RRR/EEE}$ NBD added. Now, most of the Hsc70 no longer co-elutes with clathrin because the GG/ED,RRR/EEE NBD does not bind to Hsp110.

processed for electron microscopy (Morgan et al., 2004; Bourne et al., 2006). At control synapses, after stimulation, the presynaptic plasma membrane was only slightly ruffled in appearance (Fig. $8 A$ ), which is consistent with the rate of SV endocytosis being sufficient to keep up with the rate at which SVs are exocytosed (Morgan et al., 2004; Bourne et al., 2006). However, at synapses treated with the GG/ED NBD, there was a substantial increase in the plasma membrane surface area, causing deep evaginations to form adjacent to the synaptic active zone (Fig. 8B). This periactive zone where the deep evaginations occur is the normal locale for clathrin-mediated SV endocytosis at the reticulospinal synapses (Shupliakov et al., 1997; Ringstad et al., 1999; Morgan et al., 2004; Sundborger et al., 2011). Quantification revealed that the GG/ED NBD induced a $30 \%$ increase in the size of plasma membrane evaginations, which was statistically significant (Fig.
8D; control: $2161 \pm 90 \mathrm{~nm}, n=34$; NBD GG/ED: $2921 \pm 204$ $\mathrm{nm}, n=20$ synapses; ANOVA analysis $\left.p=3 \times 10^{-4}\right)$. The expansion in the plasma membrane is consistent with the hypothesis that sequestration of NEFs by the GG/ED NBD inhibits the release of clathrin from Hsc70, thereby inhibiting clathrinmediated SV endocytosis from the plasma membrane.

The expectation that sequestering $\mathrm{Hsc} 70$ and clathrin in $\mathrm{Hsc} 70^{*}$ clathrin complexes would deplete free clathrin and inhibit endocytosis is based on our finding that Hsc70 is in $>10$-fold excess of clathrin in brain cytosol (Fig. $4 A, B$ ). If, instead, clathrin were in excess of $\mathrm{Hsc} 70$, then trapping $\mathrm{Hsc70}$ in $\mathrm{Hsc} 70^{*}$ clathrin complexes would deplete free $\mathrm{Hsc70}$ and inhibit Hsc70dependent uncoating. We would then expect to observe an increase in CCV number upon microinjection of GG/ED NBD, as has been observed with other inhibitors of Hsc70-dependent un- 

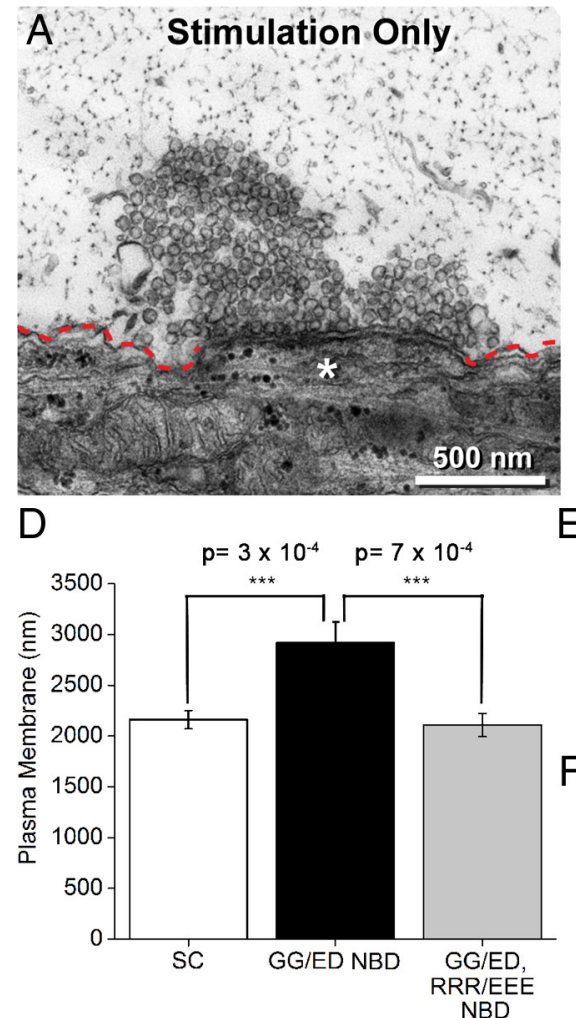

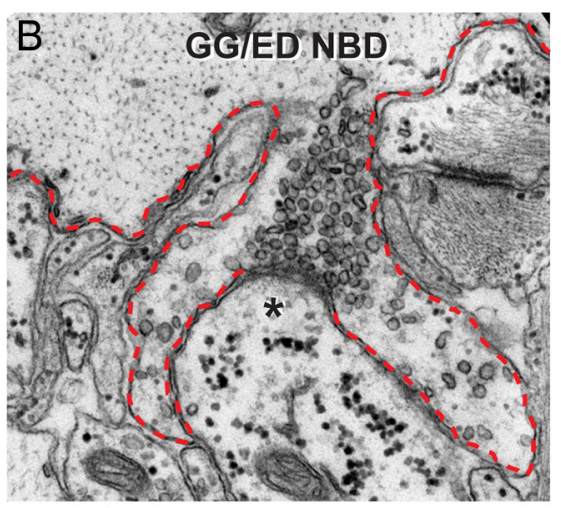

E
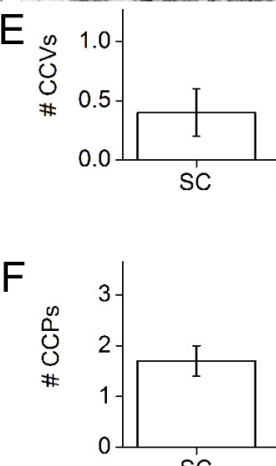

SC
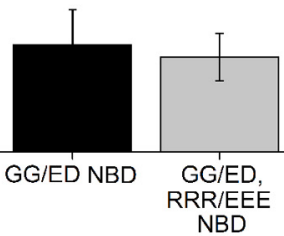

Figure 8. Hsc70 GG/ED NBD inhibits SV endocytosis from the plasma membrane. $\boldsymbol{A}$, A control synapse after buffer injection and stimulation (20 Hz, 5 min). The plasma membrane (highlighted in red) is only moderately ruffled in appearance because SV endocytosis is able to keep up with exocytosis. $\boldsymbol{B}$, In contrast, after treatment with Hsc70 GG/ED NBD and stimulation, synapses exhibit enlarged plasma membrane evaginations due to inhibition of vesicle retrieval from the plasma membrane. $C$, The endocytic defect is not observed after injection of the Hsc70 GG/ED, RRR/EEE NBD, indicating that disruption of the NBD interaction with Hsp110 disrupts its ability to inhibit endocytosis. Scale in $\boldsymbol{A}$ applies to $\boldsymbol{A}-\boldsymbol{C}$. Asterisks mark postsynaptic dendrites. $\boldsymbol{D}, \mathrm{Quantification}$ of the size of plasma membrane evaginations from 20 to 34 synapses per experimental condition. Bars represent mean \pm SEM. Asterisks indicate statistical significance using ANOVA. $\boldsymbol{E}$, Quantification of the number of CCVs from 20 to 34 synapses per experimental condition. Bars represent mean \pm SEM. $\boldsymbol{F}$, Quantification of the number of CCPs from 20 to 34 synapses per experimental condition. Bars represent mean \pm SEM. G, Quantification of the number of SV s from 20 to 34 synapses per experimental condition. Bars represent mean \pm SEM.

coating (Morgan et al., 2001; Yim et al., 2010; Fig. 1B). However, we found no significant difference in the number of CCVs at control synapses versus those treated with GG/ED NBD (Fig. 8E; stimulation control: $0.4 \pm 0.2, n=34$; GG/ED NBD: $0.9 \pm 0.3$; $n=20$ synapses), indicating that the GG/ED NBD does not significantly deplete Hsc70 available for uncoating.

There was also no statistically significant difference in the number of clathrin coated pits (CCPs), the coated structures that have not yet undergone fission (Fig. $8 F$; stimulation control: $1.7 \pm 0.3, n=34$; GG/ED NBD: $2.5 \pm 0.5 ; n=20$ synapses), or SVs (Fig. $8 G$; stimulation control: $116 \pm 9, n=34$; GG/ED NBD: $93 \pm 10 ; n=20$ synapses) between the control versus GG/ED NBD-injected preparations. A priori, it might be expected that the plasma membrane expansion produced by the GG/ED NBD would be accompanied by a decrease in the number of SVs. However, to quantitatively account for the observed 30\% increase in plasma membrane evaginations requires that only a small number of vesicles become trapped at the cell surface. One can estimate how much membrane each vesicle adds to the plasma membrane as follows: $\pi \times \mathrm{SV}$ diameter $=3.14 \times 45 \mathrm{~nm}=\sim 141$ $\mathrm{nm} /$ vesicle. In single thin sections, the plasma membrane evaginations in NEF-inhibited conditions were on average $760 \mathrm{~nm}$ larger than in control conditions, corresponding to five to six additional vesicles per section being trapped at the plasma membrane. This falls well within the biological variability observed in the sizes of vesicle clusters under uninhibited, control stimulation conditions (Fig. 8G).
To test the hypothesis that it is specifically Hsp110 that releases clathrin from $\mathrm{Hsc70}$ at nerve terminals, we injected giant reticulospinal axons with Hsc70 GG/ED,RRR/EEE NBD and characterized its synaptic effects as described above. This mutant shows no detectable interaction with Hsp110 by native PAGE (Fig. 5), is at least 1500-fold less efficient than the Hsc70 GG/ED NBD at inhibiting the Hsp110-mediated stimulation of clathrin basket disassembly (Fig. 3, Fig. 6), and does not block Hsp110mediated disruption of clathrin ${ }^{\star} \mathrm{Hsc70}$ interactions (Fig. 7D). However, Hsc70 GG/ED,RRR/EEE NBD still binds to Bag1, and its effect on Bag1-mediated stimulation of uncoating is statistically indistinguishable from Hsc70 GG/ED NBD (Fig. 3, Fig. 5, Fig. 6). Therefore, if Hsp1 10 is the biologically relevant NEF during SV endocytosis, then GG/ED,RRR/EEE NBD should not inhibit endocytosis from the plasma membrane. However, if Bag1 or another protein is the biologically relevant NEF, then this mutant should still inhibit endocytosis. When we injected giant reticulospinal axons with the GG/ED,RRR/EEE NBD, we found no significant difference in the sizes of plasma membrane evaginations compared with control stimulated synapses, whereas the difference in plasma membrane evaginations compared with the GG/ED NBD-treated synapses was highly significant (stimulation control: $2161 \pm 90 \mathrm{~nm}, n=34$; GG/ED NBD: $2921 \pm 204$, $n=20$; GG/ED,RRR/EEE NBD: $2109 \pm 114, n=26$; ANOVA analysis $p=7 \times 10^{-4}$; compare Fig. $8 D$, Fig. $\left.8 A-C\right)$. Given that there were no significant differences in the number of CCVs, CCPs, or SVs between the control and Hsc70 GG/ED NBD 
groups, we did not expect to see any difference with Hsc70 GG/ ED, RRR/EEE NBD and, indeed, the CCV, CCP, and SV numbers for all three groups were statistically indistinguishable (Fig. $8 E-$ $G)$. Therefore, the RRR/EEE mutation that specifically abolishes GG/ED NBD binding and inhibition of Hsp110 in vitro also abolishes GG/ED NBD inhibition of endocytosis in vivo. These data indicate that Hsp110 is the biologically relevant NEF during SV endocytosis at nerve terminals.

\section{Discussion}

The roles of Hsc70 and its co-chaperone auxilin in CCV uncoating in vivo are well established (Rothman and Schmid, 1986; Ungewickell et al., 1995; Morgan et al., 2001; Yim et al., 2010). However, only recently have in vitro experiments suggested a role for another Hsc70 regulator, the NEFs, in clathrin-mediated endocytosis (Schuermann et al., 2008). Experiments presented in our previous study showed that when Hsc70 is limiting in vitro, NEFs stimulate CCV uncoating by disrupting the stable clathrin: Hsc70*ADP complexes that form upon clathrin basket disassociation, allowing Hsc70 to participate in multiple rounds of uncoating (Schuermann et al., 2008). In neuronal cytosol, however, we found that Hsc70 is not limiting but is in large excess of clathrin (Fig. 4). Therefore, because Hsc70 is such an abundant molecule, the ability of Hsp110 to disrupt clathrin:Hsc70 complexes may not be required to make Hsc70 available for uncoating. Instead, it may be that the NEF action is required to dissociate the Hsc70:clathrin complexes to make clathrin available for endocytosis. The experiments described here support this model, because inhibiting NEF function with an inhibitor (GG/ED NBD) that sequesters Hsp70 NEFs results in a 30\% expansion of the presynaptic plasma membrane at live synapses (Fig. 8). Similarly, a plasma membrane expansion has been observed in vivo at squid, lamprey, and mammalian synapses when reagents that interact with clathrin and inhibit the early stages of clathrin-mediated SV endocytosis have been characterized (Morgan et al., 1999; Morgan et al., 2000; von Kleist et al., 2011). Our results therefore represent the first in vivo data supporting a model in which NEFs function at synapses to release clathrin from a complex with $\mathrm{Hsc70}$, so that the clathrin can participate in continued rounds of SV endocytosis.

At first, it might seem perplexing that there was no significant decrease in the number of SVs to accompany the increase in plasma membrane in the presence of the NEF inhibitor (GG/ED NBD). However, an analysis across several studies indicates that we would not expect to see this under conditions in which there is only a $30 \%$ increase in plasma membrane. For example, a peptide inhibitor of the talin:PIP kinase interaction resulted in a $100 \%$ increase in plasma membrane and a 30\% decrease in SV number at lamprey reticulospinal synapses that were stimulated under conditions identical to those used here (Morgan et al., 2004). In that same study, the head domain of talin protein (which similarly competes for endogenous talin:PIP kinase interactions) led to an $80 \%$ increase in plasma membrane, although in this case, no statistically significant change in SVs (Morgan et al., 2004). The lesser effects of the protein inhibitor were attributed to its necessarily being used at lower concentrations than the peptide. Therefore, a comparison of these parameters reveals that the increase in plasma membrane has to be very large (approaching 100\%) to give rise to statistically significant changes in SV number, a conclusion that is supported by additional studies at lamprey synapses using different reagents and stimulation conditions (Gad et al., 1998; von Kleist et al., 2011). The increase in plasma membrane that we observed with GG/ED NBD, also a protein inhibi- tor, is only $30 \%$, which amounts to five to six additional SVs being trapped in the plasma membrane; therefore, we would not expect to see a significant reduction of SVs. That we observed a smaller expansion of the plasma membrane than was seen in previous studies may reflect the mechanism of our inhibitor, which indirectly depletes available clathrin by sequestering the NEFs that are required to dissociate clathrin:Hsc70 complexes. If the sequestration of the NEFs is not $100 \%$ efficient, then the remaining fraction of free NEFs, which act catalytically, may dissociate a significant fraction of the clathrin:Hsc70 complexes. In addition, even in the absence of a NEF, these complexes dissociate spontaneously, albeit at a slow rate. The NEF inhibitor is therefore expected to reduce, but not eliminate, the amount of free clathrin. This reduced free clathrin may therefore be sufficient to sustain a significant but decreased amount of endocytosis.

The increase in plasma membrane that we observed with the NEF inhibitor GG/ED NBD was statistically significant and was associated with the distinctive perisynaptic evaginations characteristic of endocytic inhibition at lamprey synapses. The GG/ED NBD can bind and inhibit Bag1, Hsp110, and, based on available crystal structures, it would be expected to bind all other known Hsp70 NEFs. When we mutated a positively charged region (R299/R301/R311) of the GG/ED NBD, which interacts with Hsp110, but not with other known Hsc70 NEFs or cochaperones, binding to Hsp110, but not Bag1, was disrupted. Our double-blind EM analysis revealed that this mutation also abrogated the ability of the inhibitor to induce plasma membrane expansion at the lamprey synapse. This indicates that it is the inhibition of Hsp110 that is responsible for the plasma membrane changes seen in the presence of GG/ED NBD. The endocytic inhibition that we observed with GG/ED NBD (but not GG/ED RRR/EEE NBD) allows us to conclude that Hsp110 activity is normally required at neuronal synapses to dissociate clathrin:Hsc70 complexes and make sufficient clathrin available to sustain efficient SV endocytosis. That Hsp110 is the physiologically relevant NEF involved in dissociating these complexes at nerve terminals is also supported by the observation that Hsp110 is highly abundant in brain cytosol, being present at levels comparable to Hsc70 and >100 times in excess of Bag 1 (Fig. 4).

The persistence of the clathrin:Hsc70 interaction after uncoating, and the consequent requirement for a NEF to dissociate this complex, may very well be a response to the highly self-interactive nature of the clathrin molecule, which, in addition to being assembled by adaptor proteins into regular coat structures at the plasma membrane during endocytosis, is also capable of spontaneous assembly into irregular polymeric structures and empty baskets of heterogeneous size and shape (Ye and Lafer, 1995). $\mathrm{Hsc70}$ may therefore be required to chaperone clathrin in vivo to prevent such aberrant polymerization, and Hsc70 is sufficiently abundant to bind and chaperone all of the depolymerized clathrin at the nerve terminal (Fig. 4), as well as in other cell types and compartments. Consistent with this, immunoprecipitation of clathrin from neurons coprecipitates Hsc70 (Black et al., 1991) and expression of mutant Hsc70s with reduced ATP binding/ hydrolysis and unstable clathrin binding leads to aberrant clathrin polymerization in vivo (Newmyer and Schmid, 2001).

The ATP-dependent cycles of the abundant and numerous Hsp70 family members control much of the protein folding, trafficking, complex remodeling, and general protein processing reactions in eukaryotic cells. Furthermore, Hsp110 is now believed to be the predominant NEF for Hsp70 (Xu et al., 2012), as well as being directly involved in binding and disaggregating misfolded 
proteins (Polier et al., 2010; Shorter, 2011). The NEF inhibitors created and characterized in this study (Fig. 3, Fig. 4, Fig. 5, Fig. 6, Fig. 7, Fig. 8) should therefore have broad utility for examining the role of Hsp70 NEFs in other cell biological processes.

\section{References}

Ahle S, Ungewickell E (1986) Purification and properties of a new clathrin assembly protein. EMBO J 5:3143-3149. Medline

Arakawa A, Handa N, Ohsawa N, Shida M, Kigawa T, Hayashi F, Shirouzu M, Yokoyama S (2010) The C-terminal BAG domain of BAG5 induces conformational changes of the Hsp70 nucleotide-binding domain for ADPATP exchange. Structure 18:309-319. CrossRef Medline

Augustine GJ, Morgan JR, Villalba-Galea CA, Jin S, Prasad K, Lafer EM (2006) Clathrin and synaptic vesicle endocytosis: studies at the squid giant synapse. Biochem Soc Trans 34:68-72. CrossRef Medline

Black MM, Chestnut MH, Pleasure IT, Keen JH (1991) Stable clathrin: uncoating protein (hsc70) complexes in intact neurons and their axonal transport. J Neurosci 11:1163-1172. Medline

Blondeau F, Ritter B, Allaire PD, Wasiak S, Girard M, Hussain NK, Angers A, Legendre-Guillemin V, Roy L, Boismenu D, Kearney RE, Bell AW, Bergeron JJ, McPherson PS (2004) Tandem MS analysis of brain clathrin-coated vesicles reveals their critical involvement in synaptic vesicle recycling. Proc Natl Acad Sci U S A 101:3833-3838. CrossRef Medline

Bourne J, Morgan JR, Pieribone VA (2006) Actin polymerization regulates clathrin coat maturation during early stages of synaptic vesicle recycling at lamprey synapses. J Comp Neurol 497:600-609. CrossRef Medline

Brehmer D, Gässler C, Rist W, Mayer MP, Bukau B (2004) Influence of GrpE on DnaK-substrate interactions. J Biol Chem 279:27957-27964. CrossRef Medline

Brodin L, Shupliakov O (2006) Giant reticulospinal synapse in lamprey: molecular links between active and periactive zones. Cell Tissue Res 326: 301-310. CrossRef Medline

Cutress RI, Townsend PA, Sharp A, Maison A, Wood L, Lee R, Brimmell M, Mullee MA, Johnson PW, Royle GT, Bateman AC, Packham G (2003) The nuclear BAG-1 isoform, BAG-1L, enhances oestrogen-dependent transcription. Oncogene 22:4973-4982. CrossRef Medline

Dittman J, Ryan TA (2009) Molecular circuitry of endocytosis at nerve terminals. Annu Rev Cell Dev Biol 25:133-160. CrossRef Medline

Dragovic Z, Broadley SA, Shomura Y, Bracher A, Hartl FU (2006) Molecular chaperones of the Hsp110 family act as nucleotide exchange factors of Hsp70s. EMBO J 25:2519-2528. CrossRef Medline

Flaherty KM, Wilbanks SM, DeLuca-Flaherty C, McKay DB (1994) Structural basis of the 70-kilodalton heat shock cognate protein ATP hydrolytic activity. II. Structure of the active site with ADP or ATP bound to wild type and mutant ATPase fragment. J Biol Chem 269:12899-12907. Medline

Ford MG, Pearse BM, Higgins MK, Vallis Y, Owen DJ, Gibson A, Hopkins CR, Evans PR, McMahon HT (2001) Simultaneous binding of PtdIns(4,5)P2 and clathrin by AP180 in the nucleation of clathrin lattices on membranes. Science 291:1051-1055. CrossRef Medline

Gad H, Löw P, Zotova E, Brodin L, Shupliakov O (1998) Dissociation between $\mathrm{Ca}^{2+}$-triggered synaptic vesicle exocytosis and clathrin-mediated endocytosis at a central synapse. Neuron 21:607-616. CrossRef Medline

Gässler CS, Wiederkehr T, Brehmer D, Bukau B, Mayer MP (2001) Bag-1M accelerates nucleotide release for human Hsc70 and Hsp70 and can act concentration-dependent as positive and negative cofactor. J Biol Chem 276:32538-32544. CrossRef Medline

González-Gaitán M, Jackle H (1997) Role of Drosophila alpha-adaptin in presynaptic vesicle recycling. Cell 88:767-776. CrossRef Medline

Hao W, Tan Z, Prasad K, Reddy KK, Chen J, Prestwich GD, Falck JR, Shears SB, Lafer EM (1997) Regulation of AP-3 function by inositides. Identification of phosphatidylinositol 3,4,5-trisphosphate as a potent ligand. J Biol Chem 272:6393-6398. CrossRef Medline

Hao W, Luo Z, Zheng L, Prasad K, Lafer EM (1999) AP180 and AP-2 interact directly in a complex that cooperatively assembles clathrin. J Biol Chem 274:22785-22794. CrossRef Medline

Harrison CJ, Hayer-Hartl M, Di Liberto M, Hartl F, Kuriyan J (1997) Crystal structure of the nucleotide exchange factor GrpE bound to the ATPase domain of the molecular chaperone DnaK. Science 276:431-435. CrossRef Medline

Ishihara K, Yasuda K, Hatayama T (1999) Molecular cloning, expression and localization of human $105 \mathrm{kDa}$ heat shock protein, hsp105. Biochim Biophys Acta 1444:138-142. CrossRef Medline

Jiang J, Prasad K, Lafer EM, Sousa R (2005) Structural basis of interdomain communication in the Hsc70 chaperone. Mol Cell 20:513-524. CrossRef Medline

Jiang J, Maes EG, Taylor AB, Wang L, Hinck AP, Lafer EM, Sousa R (2007) Structural basis of J cochaperone binding and regulation of Hsp70. Mol Cell 28:422-433. CrossRef Medline

Jiang R, Gao B, Prasad K, Greene LE, Eisenberg E (2000) Hsc70 chaperones clathrin and primes it to interact with vesicle membranes. J Biol Chem 275:8439-8447. CrossRef Medline

Jung N, Haucke V (2007) Clathrin-mediated endocytosis at synapses. Traffic 8:1129-1136. CrossRef Medline

Keen JH (1987) Clathrin assembly proteins: affinity purification and a model for coat assembly. J Cell Biol 105:1989-1998. CrossRef Medline

Keen JH, Willingham MC, Pastan IH (1979) Clathrin-coated vesicles: isolation, dissociation and factor-dependent reassociation of clathrin baskets. Cell 16:303-312. CrossRef Medline

Mayer MP, Schröder H, Rudiger S, Paal K, Laufen T, Bukau B (2000) Multistep mechanism of substrate binding determines chaperone activity of Hsp70. Nat Struct Biol 7:586-593. CrossRef Medline

Mettlen M, Pucadyil T, Ramachandran R, Schmid SL (2009) Dissecting dynamin's role in clathrin-mediated endocytosis. Biochem Soc Trans 37: 1022-1026. CrossRef Medline

Morgan JR, Zhao X, Womack M, Prasad K, Augustine GJ, Lafer EM (1999) A role for the clathrin assembly domain of AP180 in synaptic vesicle endocytosis. J Neurosci 19:10201-10212. Medline

Morgan JR, Prasad K, Hao W, Augustine GJ, Lafer EM (2000) A conserved clathrin assembly motif essential for synaptic vesicle endocytosis. J Neurosci 20:8667-8676. Medline

Morgan JR, Prasad K, Jin S, Augustine GJ, Lafer EM (2001) Uncoating of clathrin-coated vesicles in presynaptic terminals: roles for Hsc70 and auxilin. Neuron 32:289-300. CrossRef Medline

Morgan JR, Augustine GJ, Lafer EM (2002) Synaptic vesicle endocytosis: the races, places, and molecular faces. Neuromol Med 2:101-114. CrossRef Medline

Morgan JR, Prasad K, Jin S, Augustine GJ, Lafer EM (2003) Eps15 homology domain-NPF motif interactions regulate clathrin coat assembly during synaptic vesicle recycling. J Biol Chem 278:33583-33592. CrossRef Medline

Morgan JR, Di Paolo G, Werner H, Shchedrina VA, Pypaert M, Pieribone VA, De Camilli P (2004) A role for talin in presynaptic function. J Cell Biol 167:43-50. CrossRef Medline

Nandi PK, Irace G, Van Jaarsveld PP, Lippoldt RE, Edelhoch H (1982) Instability of coated vesicles in concentrated sucrose solutions. Proc Natl Acad Sci U S A 79:5881-5885. CrossRef Medline

Newmyer SL, Schmid SL (2001) Dominant-interfering Hsc70 mutants disrupt multiple stages of the clathrin-coated vesicle cycle in vivo. J Cell Biol 152:607-620. CrossRef Medline

Oliphint PA, Alieva N, Foldes AE, Tytell ED, Lau BYB, Pariseau JS, Cohen AH, Morgan JR (2010) Regenerated synapses in Lamprey spinal cord are sparse and small even after functional recovery from injury. J Comp Neurol 518:2854-2872. CrossRef Medline

Pearse BM (1975) Coated vesicles from pig brain: purification and biochemical characterization. J Mol Biol 97:93-98. CrossRef Medline

Pieribone VA, Shupliakov O, Brodin L, Hilfiker-Rothenfluh S, Czernik AJ, Greengard P (1995) Distinct pools of synaptic vesicles in neurotransmitter release. Nature 375:493-497. CrossRef Medline

Polier S, Dragovic Z, Hartl FU, Bracher A (2008) Structural basis for the cooperation of Hsp70 and Hsp110 chaperones in protein folding. Cell 133:1068-1079. CrossRef Medline

Polier S, Hartl FU, Bracher A (2010) Interaction of the Hsp110 molecular chaperones from S. cerevisiae with substrate protein. J Mol Biol 401:696707. CrossRef Medline

Rapoport I, Boll W, Yu A, Böcking T, Kirchhausen T (2008) A motif in the clathrin heavy chain required for the hsc70/auxilin uncoating reaction. Mol Biol Cell 19:405-413. CrossRef Medline

Raviol H, Bukau B, Mayer MP (2006) Human and yeast Hsp1 10 chaperones exhibit functional differences. FEBS Lett 580:168-174. CrossRef Medline

Ringstad N, Gad H, Löw P, Di Paolo G, Brodin L, Shupliakov O, De Camilli P (1999) Endophilin/SH3p4 is required for the transition from early to late 
stages in clathrin-mediated synaptic vesicle endocytosis. Neuron 24:143154. CrossRef Medline

Rothman JE, Schmid SL (1986) Enzymatic recycling of clathrin from coated vesicles. Cell 46:5-9. CrossRef Medline

Saheki Y, De Camilli P (2012) Synaptic vesicle endocytosis. Cold Spring Harb Perspect Biol. 4:a005645. CrossRef Medline

Schlieker C, Bukau B, Mogk A (2002) Prevention and reversion of protein aggregation by molecular chaperones in the E. coli cytosol: implications for their applicability in biotechnology. J Biotechnol 96:13-21. CrossRef Medline

Schröder H, Langer T, Hartl FU, Bukau B (1993) DnaK, DnaJ and GrpE form a cellular chaperone machinery capable of repairing heat-induced protein damage. EMBO J 12:4137-4144. Medline

Schuermann JP, Jiang J, Cuellar J, Llorca O, Wang L, Gimenez LE, Jin S, Taylor AB, Demeler B, Morano KA, Hart PJ, Valpuesta JM, Lafer EM, Sousa R (2008) Structure of the Hsp110:Hsc70 nucleotide exchange machine. Mol Cell 31:232-243. CrossRef Medline

Shaner L, Sousa R, Morano KA (2006) Characterization of Hsp70 binding and nucleotide exchange by the yeast Hsp110 chaperone Sse1. Biochemistry 45:15075-15084. CrossRef Medline

Shomura Y, Dragovic Z, Chang HC, Tzvetkov N, Young JC, Brodsky JL, Guerriero V, Hartl FU, Bracher A (2005) Regulation of Hsp70 function by HspBP1: structural analysis reveals an alternate mechanism for Hsp70 nucleotide exchange. Mol Cell 17:367-379. CrossRef Medline

Shorter J (2011) The mammalian disaggregase machinery: Hsp110 synergizes with Hsp70 and Hsp40 to catalyze protein disaggregation and reactivation in a cell-free system. PLoS One 6:e26319. CrossRef Medline

Shupliakov O, Löw P, Grabs D, Gad H, Chen H, David C, Takei K, De Camilli P, Brodin L (1997) Synaptic vesicle endocytosis impaired by disruption of dynamin-SH3 domain interactions. Science 276:259-263. CrossRef Medline

Sondermann H, Scheufler C, Schneider C, Hohfeld J, Hartl FU, Moarefi I (2001) Structure of a Bag/Hsc70 complex: convergent functional evolution of Hsp70 nucleotide exchange factors. Science 291:1553-1557. CrossRef Medline

Sundborger A, Soderblom C, Vorontsova O, Evergren E, Hinshaw JE, Shupliakov O (2011) An endophilin-dynamin complex promotes budding of clathrin-coated vesicles during synaptic vesicle recycling. J Cell Sci 124:133-143. CrossRef Medline

Szabo A, Langer T, Schröder H, Flanagan J, Bukau B, Hartl FU (1994) The ATP hydrolysis-dependent reaction cycle of the Escherichia coli Hsp70 system DnaK, DnaJ, and GrpE. Proc Natl Acad Sci U S A 91:10345-10349. CrossRef Medline

Takeda S, McKay DB (1996) Kinetics of peptide binding to the bovine 70 $\mathrm{kDa}$ heat shock cognate protein, a molecular chaperone. Biochemistry 35:4636-4644. CrossRef Medline

Takei K, McPherson PS, Schmid SL, De Camilli P (1995) Tubular membrane invaginations coated by dynamin rings are induced by GTP-gamma S in nerve terminals. Nature 374:186-190. CrossRef Medline
Theyssen H, Schuster HP, Packschies L, Bukau B, Reinstein J (1996) The second step of ATP binding to DnaK induces peptide release. J Mol Biol 263:657-670. CrossRef Medline

Ungewickell E, Ungewickell H, Holstein SE, Lindner R, Prasad K, Barouch W, Martin B, Greene LE, Eisenberg E (1995) Role of auxilin in uncoating clathrin-coated vesicles. Nature 378:632-635. CrossRef Medline

von Kleist L, Stahlschmidt W, Bulut H, Gromova K, Puchkov D, Robertson MJ, MacGregor KA, Tomlin N, Pechstein A, Chau N, Chircop M, Sakoff J, von Kries JP, Saenger W, Kräusslich HG, Shupliakov O, Robinson PJ, McCluskey A, Haucke V (2011) Role of the clathrin terminal domain in regulating coated pit dynamics revealed by small molecule inhibition. Cell 146:471-484. CrossRef Medline

Weibezahn J, Tessarz P, Schlieker C, Zahn R, Maglica Z, Lee S, Zentgraf H, Weber-Ban EU, Dougan DA, Tsai FT, Mogk A, Bukau B (2004) Thermotolerance requires refolding of aggregated proteins by substrate translocation through the central pore of ClpB. Cell 119:653-665. CrossRef Medline

Weibezahn J, Schlieker C, Tessarz P, Mogk A, Bukau B (2005) Novel insights into the mechanism of chaperone-assisted protein disaggregation. Biol Chem 386:739-744. CrossRef Medline

Xing Y, Böcking T, Wolf M, Grigorieff N, Kirchhausen T, Harrison SC (2010) Structure of clathrin coat with bound $\mathrm{Hsc70}$ and auxilin: mechanism of Hsc70-facilitated disassembly. EMBO J 29:655-665. CrossRef Medline

Xu X, Sarbeng EB, Vorvis C, Kumar DP, Zhou L, Liu Q (2012) Unique peptide substrate binding properties of $110-\mathrm{kDa}$ heat-shock protein (Hsp110) determine its distinct chaperone activity. J Biol Chem 287: 5661-5672. CrossRef Medline

Xu Z, Page RC, Gomes MM, Kohli E, Nix JC, Herr AB, Patterson C, Misra S (2008) Structural basis of nucleotide exchange and client binding by the Hsp70 cochaperone Bag2. Nat Struct Mol Biol 15:1309-1317. CrossRef Medline

Ye W, Lafer EM (1995) Bacterially expressed F1-20/AP-3 assembles clathrin into cages with a narrow size distribution: implications for the regulation of quantal size during neurotransmission. J Neurosci Res 41:15-26. CrossRef Medline

Yim YI, Sun T, Wu LG, Raimondi A, De Camilli P, Eisenberg E, Greene LE (2010) Endocytosis and clathrin-uncoating defects at synapses of auxilin knockout mice. Proc Natl Acad Sci U S A 107:4412-4417. CrossRef Medline

Zhang B (2003) Genetic and molecular analysis of synaptic vesicle recycling in Drosophila. J Neurocytol 32:567-589. CrossRef Medline

Zhang B, Koh YH, Beckstead RB, Budnik V, Ganetzky B, Bellen HJ (1998) Synaptic vesicle size and number are regulated by a clathrin adaptor protein required for endocytosis. Neuron 21:1465-1475. CrossRef Medline

Zhou S, Tannery NH, Yang J, Puszkin S, Lafer EM (1993) The synapsespecific phosphoprotein F1-20 is identical to the clathrin assembly protein AP-3. J Biol Chem 268:12655-12662. Medline 